\title{
Peripheral nerve conduits: technology update
}

This article was published in the following Dove Press journal:

Medical Devices: Evidence and Research

I December 2014

Number of times this article has been viewed

\section{Arslantunali ${ }^{1-3, *}$ \\ T Dursun $1,2, *$ \\ D Yucel ${ }^{1,4,5}$ \\ N Hasirci ${ }^{1,2,6}$ \\ $\checkmark$ Hasirci ${ }^{1,2,7}$}

'BIOMATEN, Center of Excellence in Biomaterials and Tissue Engineering, Middle East Technical University (METU), Ankara, Turkey; ${ }^{2}$ Department of Biotechnology, METU, Ankara, Turkey; ${ }^{3}$ Department of Bioengineering, Gumushane University, Gumushane, Turkey; ${ }^{4}$ Faculty of Engineering, Department of Medical Engineering, Acibadem University, Istanbul, Turkey; ${ }^{5}$ School of Medicine, Department of Histology and Embryology, Acibadem University, Istanbul, Turkey; ${ }^{6}$ Department of Chemistry, Faculty of Arts and Sciences, METU, Ankara, Turkey; ${ }^{7}$ Department of Biological Sciences, Faculty of Arts and Sciences, METU, Ankara, Turkey

*These authors have contributed equally to this work
Correspondence: $\mathrm{V}$ Hasirci BIOMATEN, Center of Excellence in Biomaterials and Tissue Engineering, Middle East Technical University (METU), Ankara, Turkey

Email vhasirci@metu.edu.tr
Abstract: Peripheral nerve injury is a worldwide clinical problem which could lead to loss of neuronal communication along sensory and motor nerves between the central nervous system (CNS) and the peripheral organs and impairs the quality of life of a patient. The primary requirement for the treatment of complete lesions is a tension-free, end-to-end repair. When end-to-end repair is not possible, peripheral nerve grafts or nerve conduits are used. The limited availability of autografts, and drawbacks of the allografts and xenografts like immunological reactions, forced the researchers to investigate and develop alternative approaches, mainly nerve conduits. In this review, recent information on the various types of conduit materials (made of biological and synthetic polymers) and designs (tubular, fibrous, and matrix type) are being presented.

Keywords: peripheral nerve injury, natural biomaterials, synthetic biomaterials

\section{Introduction}

Peripheral nerve injury is a worldwide clinical problem that impairs the patient's quality of life. The central nervous system (CNS) consists of the brain and the spinal cord. The peripheral nervous system, on the other hand, is located outside the CNS and includes the cranial, spinal and peripheral nerves that conduct impulses from and to the CNS. Injury in peripheral nerves could lead to loss of neuronal communication along sensory and motor nerves between the CNS and the peripheral organs. Peripheral nerve injuries often result in painful neuropathies via reduction in motor and sensory functions and can be catastrophic for patients, drastically affecting their daily activities. ${ }^{1}$ Peripheral nerves are composed of bundles of nerve fibers and surrounding connective tissue sheaths including blood vessels (Figure 1). Each individual nerve fiber and the supporting Schwann cells are surrounded by a loose connective tissue, the endoneurium. A bundle of nerve fibers is held by collagen fibrils in the connective tissue and form fascicles surrounded by a dense connective tissue called the perineurium. Entire nerve fascicles within a nerve trunk are completely ensheathed by a dense and irregular connective tissue called epineurium, which is the outermost layer of connective tissue sheaths.

In general, peripheral nerve injuries are caused by mechanical, thermal, chemical, or ischemic damages resulting mainly from traumatic accidents or some degenerative disorders. The severity of the injury determines the functional outcome. Peripheral nerve injury is commonly assessed according to the Seddon and the Sunderland classifications..$^{2-4}$ Seddon ${ }^{2}$ categorized the injuries in increasing severity as neurapraxia, axonotmesis, and neurotmesis. ${ }^{2}$ A few years later, Sunderland classified them as 


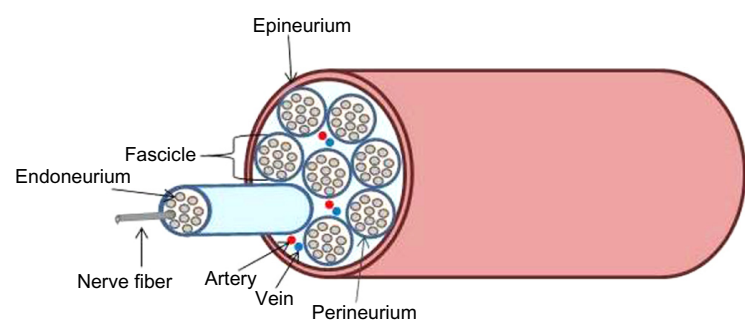

Figure I Structure of peripheral nerve trunk.

1-5 degree injuries. ${ }^{3}$ In Sunderland's first-degree injury that corresponds to neurapraxia, axons are anatomically intact and Wallerian degeneration is absent, but there is partial demyelination and impulses cannot be transmitted. These injuries recover with treatment within a few months. In Sunderland's second-degree injury, which corresponds to axonotmesis in the Seddon classification, the endoneurium and Schwann cells are intact but the axon is severed. These injuries are regenerated by the aid of intact endoneurium. In the thirddegree injury, even though the perineurium and fascicular arrangement is preserved, the endoneurium is disrupted. In these situations, fibrosis can take place within fascicles, and recovery of motor and sensory function can be significantly delayed. In fourth-degree injury, axons, endoneurium, and perineurium are disrupted, while only the outermost layer, the epineurium, is intact. There is a significantly higher degree of degeneration compared with lower-degree injuries; therefore, removal of scar tissue and surgical repair of the nerve may be needed to achieve regeneration. Sunderland's fifth degree injury corresponds to neurotmesis, where the entire nerve trunk is transected completely and there is a scar formation. As a result, neuroma and Wallerian degeneration are formed at the proximal and distal ends, respectively. In such severe injuries, surgical repair is required.

In peripheral nerve injuries that lead to axonal disruption or nerve transection, degenerative changes such as axon and myelin breakdown are initiated at the proximal and distal end of the lesion site. ${ }^{5}$ The distal end is disconnected from the neural body and undergoes Wallerian (anterograde) degeneration (Figure 2). The axonal cytoskeleton components are disassembled and the axon is fragmented. These events lead to the breakdown of myelin sheath. On the other hand, a series of cellular and molecular changes, retrograde reactions, and chromatolysis occur in the damaged neuronal cell body, and associate with retrograde axonal degeneration in the proximal nerve stump. Schwann cells and infiltrating macrophages serve in the removal of axonal, myelin, and tissue debris. In addition, Schwann cells proliferate and are aligned along external lamina to form bands of Büngner which guide the regenerative axonal sprouts that originate from the severed proximal end of the axon. New axonal sprouts undergo myelination, and these regenerated axons reach their target to attain functional recovery. The ideal progress of axonal regrowth from the proximal end is $1 \mathrm{~mm} /$ day. However, if the axonal sprouts fail to cross the injury site, this leads to formation of neuroma and the denervated muscle fiber becomes atrophic.

\section{Treatment strategies for nerve injuries}

Although the peripheral nerves have a capacity to regenerate after injury, this spontaneous nerve repair may not be sufficient to achieve proper functional recovery. The length of the nerve gap, the time passed between the injury and repair, and the patient's age are important parameters to be considered in the repair of peripheral nerve injuries. The primary medical therapy for complete lesions is a tension-free, end-to-end repair by suturing of nerve stumps via epineurial and/or group fascicular suturing. In the case of a significant nerve gap formation where end-to-end repair is not possible, peripheral nerve grafts or nerve conduits are required to serve as a bridge between the nerve stumps across the gap and to support axonal regrowth. Figure 3 presents a scheme that classifies the peripheral nerve grafts and the nerve conduit materials used.

\section{Peripheral nerve grafts}

\section{Autografts}

The most widely used nerve repair strategy, considered the "gold standard," to bridge nerve gaps is the use of autografts, harvested from the patient's own body but from another location. Nerve autografts have been studied extensively, and their superiority over epineurial suturing under tension has been reported. ${ }^{6}$ Nerve autografts provide a structural guidance of the natural material for axonal progression from the proximal to the distal nerve stumps. Functionally less important nerves like sural nerves, superficial cutaneous nerve, or lateral and medial antebrachii cutaneous nerves are chosen as donor sites for autograft nerve tissue. ${ }^{7}$ However, there are significant limitations in the use of nerve autografts, such as causing a second surgery site to harvest tissue from the donor site, which is associated with donor site morbidity and loss of function. ${ }^{5}$ Therefore, the availability and the length of nerve that can be harvested are limited. Use of autografts is currently restricted to critical nerve gaps of nearly $5 \mathrm{~cm}$ length. ${ }^{8}$ Mismatch of donor nerve size and fascicular inconsistency between the autograft and the proximal and the distal stumps 


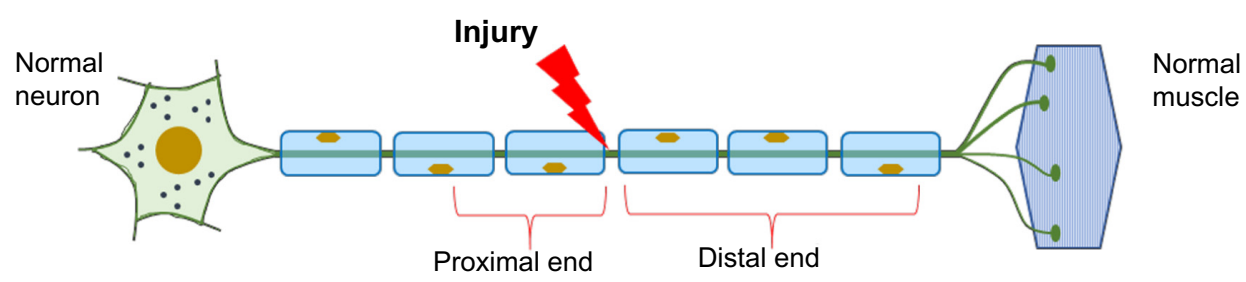

2 weeks after injury

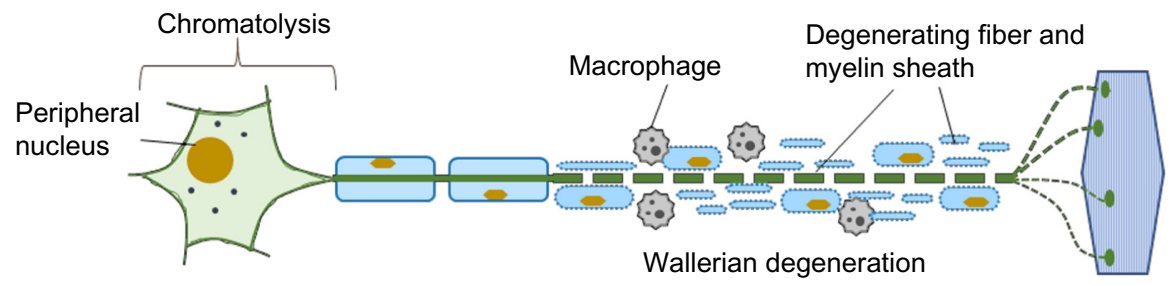

3 weeks after injury

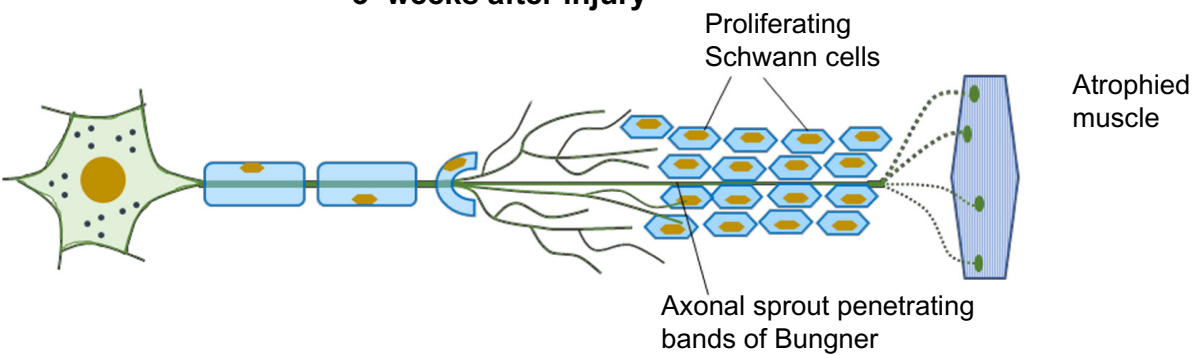

3 months after injury

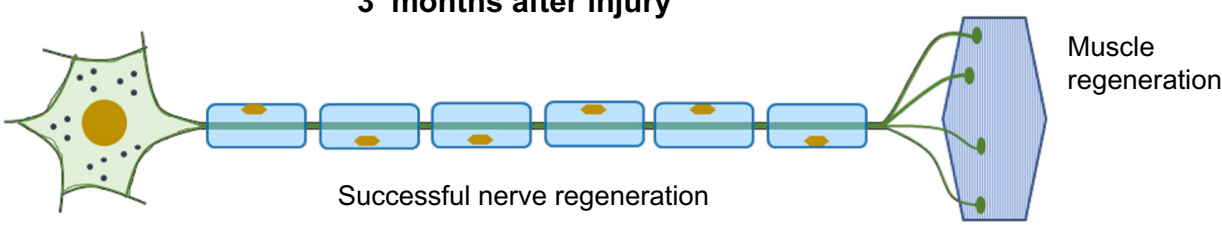

Several months after injury

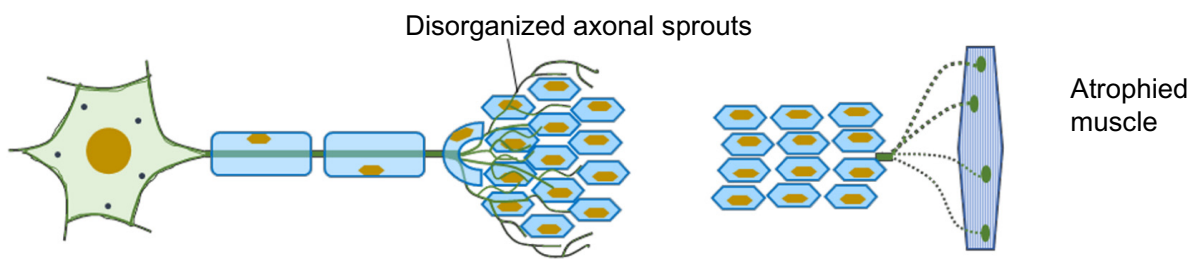

Unsuccessful nerve regeneration

Figure 2 Cellular responses to nerve injury: nerve degeneration and regeneration.

of the recipient site are the main limitations in the use of nerve autografts. In fact, the type of nerve autografts chosen, like sensory nerves, motor nerves, or mixed nerves, is also important for a successful outcome, since a mismatch in axonal size, distribution, and alignment limits the regeneration capacity of the autografts. Nichols et al ${ }^{9}$ reported that motor or mixednerve autografts are superior in axon regeneration than the sensory nerve autografts. Other important drawbacks of nerve autografts are the potential of infection and formation of painful neuroma. In addition, the recovery time for the patient can be prolonged, owing to the need for a second surgery.

The limitations of autografts forced the researchers to investigate and develop alternative approaches such as manufacturing novel nerve conduits for peripheral nerve injury. 


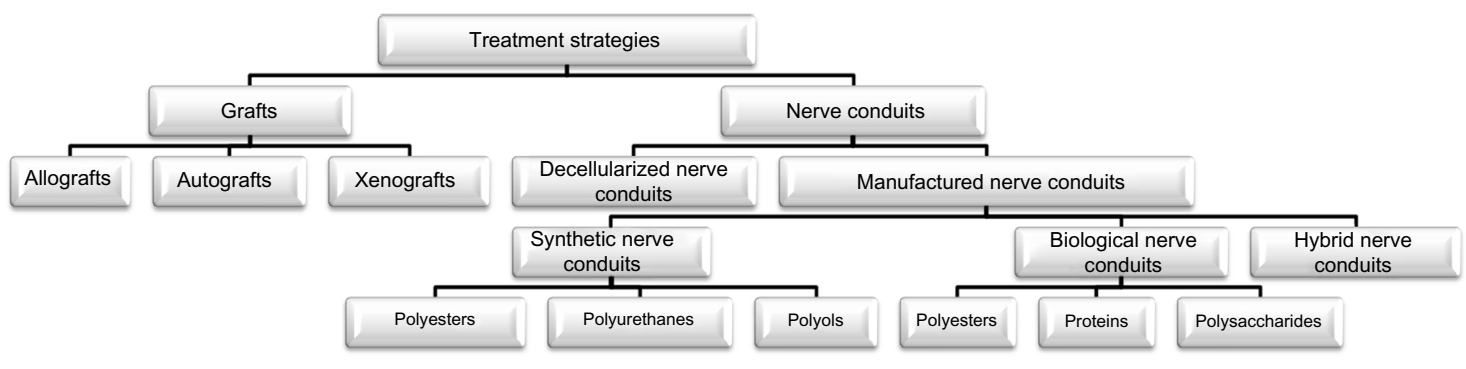

Figure 3 Classification of treatment strategies for nerve injuries.

\section{Allografts}

Nerve allograft, is a technique used to bridge a peripheral nerve lesion with tissues derived from a different individual of the same species. An allograft nerve tissue serves as a support for guidance and a source for viable donor-derived Schwann cells that would facilitate the connection of axons at the proximal and distal ends to achieve reinnervation of target tissue or organs. ${ }^{7}$ However, the use of allografts presents limitations including especially immune rejection, risk of cross contamination, secondary infection, and limited supply. Therefore, the use of allografts requires systemic immunosuppressive therapy, but long-term immune suppression is not a desirable treatment due to increased risk of infection, decrease of healing rate, and it occasionally results in tumor formation and other systemic effects. In order to overcome some of these limitations, nerve allografts can be processed by repeated freeze-thaw cycles, irradiation, and decellularization with detergents.

\section{Xenografts}

A nerve xenograft is obtained from a member of a species other than that of the recipient. ${ }^{10}$ In 1997, Hebebrand et al ${ }^{11}$ transplanted $2 \mathrm{~cm}$ sciatic nerve xenografts obtained from Golden Syrian hamsters into a $0.5 \mathrm{~cm}$ gap in the sciatic nerve of Lewis rats. The performance of this grafting procedure was assessed by walking track analysis, by measuring somatosensory-evoked potentials, and by performing histology across the nerve xenografts. The test models were immunosuppressed with RS-61443 and FK-506, and non-immunosuppressed animals were used as controls. The functional recovery in the test animals was found to be not as good as those in the control isografts. Jia et al, ${ }^{12}$ on the other hand, used acellular nerve xenografts and seeded them with bone marrow stromal cells (BMSCs). The xenografts were obtained from Sprague Dawley rats and New Zealand rabbits and introduced to $1 \mathrm{~cm}$ rat sciatic nerve gaps. When the allograft and the xenograft were compared with electrophysiological studies, it was observed that the xenografts were as effective as the allografts in regenerating the neurons. However, the risk of cross-species disease transmission would be considered for the use of xenografts.

\section{Nerve conduits}

\section{Decellularized nerve conduits}

Allografts and xenografts have the potential to induce immunogenic reactions in the host tissue. In order to suppress the immunogenic reactions, the grafts are used in combination with immunosuppressive drugs. ${ }^{13}$ However, the use of these drugs may cause more susceptibility to infections and tumor formation. ${ }^{14}$ Therefore, to eliminate the cellular constituents that cause immunogenic reactions but to preserve the native extracellular matrix (ECM) that is known to enhance the regenerative capacity, "decellularization methods" have been developed. ${ }^{15}$ Preservation of the ECM, which is conserved among the various species together with the basal lamina of allografts or xenografts, creates a means for mechanical guidance for the regenerating axons. Decellularization processes include various physical and chemical methods as well as enzymatic methods. Widely used physical methods are lyophilization, direct pressure, sonication, and agitation. ${ }^{16}$ Freezing nerve tissue causes disruption of cell membranes and results in cell lysis. ${ }^{17}$ During the freezing step, disruption of the ECM caused by rapid freezing that produces ice crystals should be avoided. Application of direct pressure is another method that has been used to decellularize the grafts. Mechanical agitation and sonication have been used together with chemical treatment to disrupt cell membranes. ${ }^{18,19}$ Chemical methods used with or without physical treatments include processes with alkaline and acid solutions, ${ }^{20,21}$ nonionic, ionic, and zwitter ionic detergents, ${ }^{15,22-24}$ and hypotonic and hypertonic solutions. ${ }^{25,26}$ Treatment with acidic or alkaline solutions solubilizes cell components and disrupts nucleic acids. Ionic detergents like sodium dodecyl sulfate and Triton X-200 also solubilize cellular components and denature proteins. However, nonionic detergents like Triton $\mathrm{X}-100$ leave protein-protein interactions intact, and this is not 
desirable. Hypotonic and hypertonic solutions like solutions of ethylenediamine tetraacetic acid (EDTA) result in osmotic shock and lead to cell lysis. Solutions like EDTA are generally used in conjunction with treatments involving enzymes such as exonucleases, endonucleases, and trypsin. ${ }^{27-29}$ The requirement for the removal of any remaining chemicals, which may cause cell damage in the host tissue after implantation, may be considered a disadvantage of decellularized graft materials. Trypsin proteolysis as an enzymatic degradation method has been widely used to decellularize dermis or heart valves, although the stability of ECM may be limited with the alteration of collagen content after trypsin treatment. . $^{23,30}$

Various studies have shown that decellularized grafts are able to promote regeneration in defects more than 1-2 cm long in a rat sciatic model. ${ }^{31-33}$ A study showed that axons do not always reach the distal segment when decellularized nerve conduits are used in the treatment of defects over 1-2 cm without the support of other components like chondroitinase. ${ }^{34}$ In that study, it was found that $4 \mathrm{~cm}$ long lyophilized, decellularized nerve allografts with chondroitinase could support regeneration along their full length. AxoGen Inc. (Alachua, FL, USA) received US Food and Drug Administration (FDA) approval for this decellularized allograft $\left(\right.$ Avance $\left.^{\circledR}\right)$. Whitlock et al ${ }^{35}$ compared Avance ${ }^{\circledR}$ with another FDA-approved commercial product Neuragen ${ }^{\circledR}$ which is a collagen-based device (discussed later in Section "Biological nerve conduits - proteins"). The performance of Avance ${ }^{\circledR}$ was evaluated in a $14 \mathrm{~mm}$ sciatic nerve-gap model, and it was found to be as good as Neuragen ${ }^{\circledR}$ and autografts demonstrated almost no difference after 12 weeks. In 2009 , Avance $^{\circledR}$ was evaluated in clinical studies, and grafts of 0.5-30 mm length were surgically implanted to two dorsal and eight digital sensory nerves of five men and two women. Evaluation based on infection, rejection, and graft extrusion revealed that nerve sensations were restored within 9 months. Sun et $\mathrm{al}^{36}$ investigated the effects of a decellularized allogeneic artery conduit containing autologous, transdifferentiated, adipose-derived stem cells (dADSCs) on an $8 \mathrm{~mm}$ long facial nerve branch lesion in a rat model. After 8 weeks, functional evaluation of vibrissae movements and electrophysiological assessment, retrograde labeling of facial motor neurons, and morphological analysis of regenerated nerves were performed to assess regeneration. Use of decellularized allogeneic artery conduits with autologous dADSCs showed definite beneficial effects on nerve regeneration and functional restoration. Zhao et $\mathrm{al}^{37}$ reported nerve regeneration achieved through the use of a decellularized nerve graft by supplementation with BMSCs in fibrin. In that study, mesenchymal stem cells (MSCs) injected around the graft helped improve nerve regeneration and functional recovery of peripheral nerve lesions as determined by functional analysis and histology.

\section{Manufactured nerve conduits}

Cylindrical nerve grafts have been used for nerve repair as early as 1879 , with the first application of bone tube used as a nerve conduit. ${ }^{38}$ Because of the scar formation, however, the experiments failed. The advantages of using nerve grafts are 1) limited myofibroblast infiltration, 2) reduced scar formation, and 3) guidance of regenerating nerves. ${ }^{39}$ Because of their limitations such as the potential to cause donor site morbidity, researchers have started designing artificial nerve conduits by using synthetic and biological polymers as an alternative treatment. An ideal nerve conduit needs to have properties like biocompatibility, biodegradability, flexibility, high porosity, compliance, neuroinductivity, neuroconductivity with appropriate surface, and mechanical properties. ${ }^{40}$ The nerve conduit may be designed in different ways; they could be cylindrical tubes with internal channels or matrix, porous walls, or cell incorporation, and the design may include bioactive agents (Figure 4). Polymeric materials having the right properties have been studied and used as nerve conduits for peripheral nerve regeneration. ${ }^{41,42}$

\section{Biological nerve conduits}

Bioactive properties of the biological polymers used in tissue engineering and in other implants allow better interactions between the cells and the scaffolds which enhance proliferation of the cells and regeneration of tissues. Although high biocompatibility of the biological polymers makes them good candidates for use as nerve conduits, they have some limitations like batch-to-batch variation. ${ }^{42}$ Among the biopolymers commonly used in nerve regeneration studies are polyesters (poly(3-hydroxybutyrate) [P3HB] and poly(3-hydroxybutyric acid-co-3-hydroxyvaleric acid)), proteins (silk, collagen, gelatin, fibrinogen, elastin, and keratin), and polysaccharides (hyaluronic acid, chiti, and alginate) constitute the majority. In Figure $5 \mathrm{~A}$ and $\mathrm{B}$, the structure of some biological polymers are presented.

\section{Polyesters}

A variety of biological polyesters are obtained from microorganisms. Polyhydroxyalkonates (PHAs) are a class of biodegradable and biocompatible, synthetic, thermoplastic polyesters that are produced by various microorganisms, such as soil bacteria, blue-green algae, and also by some 


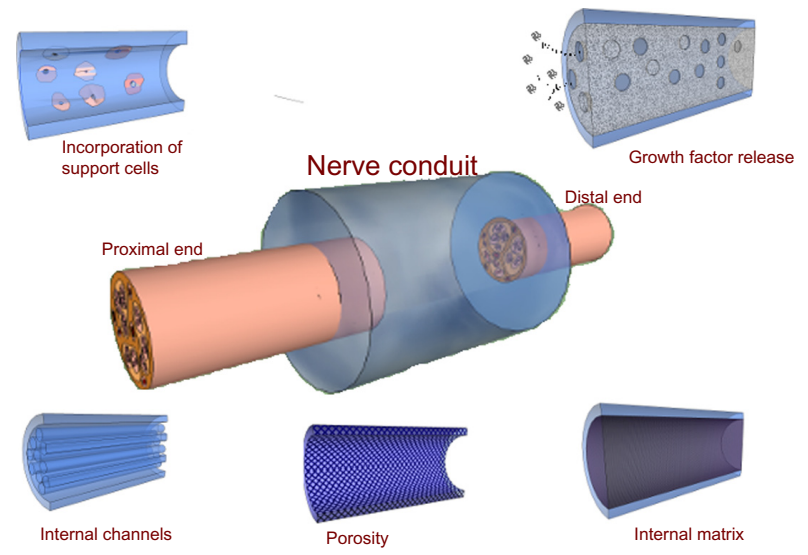

Figure 4 Examples for nerve conduit designs.

genetically modified plants (Figure 5A). ${ }^{43}$ The natural role of PHAs in microorganisms is to serve as an intracellular energy and carbon storage product. The PHAs used in the tissue engineering applications are poly(4-hydroxybutyrate), polyhydroxyvalerate, polyhydroxyhexanoate, polyhydroxyoctanoate, and $\mathrm{P} 3 \mathrm{HB}$. One of the most extensively studied PHAs in nerve regeneration is $\mathrm{P} 3 \mathrm{HB},{ }^{44}$ and another is poly(3-hydroxybutyrate-co-3-hydroxyvalerate) (PHBV).

\section{$\mathrm{P} 3 \mathrm{HB}$}

P3HB (Figure 5A) is used as a bacterial storage product and can be commercially obtained as resorbable sheets, particles, and films. It has been used in peripheral nerve regeneration studies for more than 2 decades. Wrapping polyhydroxybutyrate (PHB) sheets around nerve defects was shown to help regeneration of axons in cats. ${ }^{45}$ Aberg et al ${ }^{46}$ performed a clinical trial with $\mathrm{P} 3 \mathrm{HB}$ as a wrap around the epineurial axons and compared it with epineural suturing. Tests of up to 18 months showed that $\mathrm{P} 3 \mathrm{HB}$ yielded better results than epineurial suturing with no adverse effects. ECM proteins, Schwann cells, and nerve growth factors (NGFs) have been incorporated in order to improve the regenerative ability of the P3HB nerve conduits. ${ }^{47,48}$ In the study of Mohanna et al, ${ }^{49}$ a $\mathrm{P} 3 \mathrm{HB}$ conduit containing alginate hydrogel, or alginate

A Polyhydroxyalkanoates

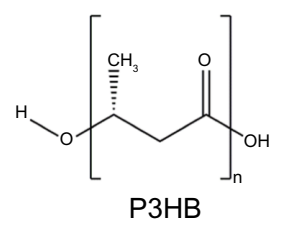

B Polysaccharides

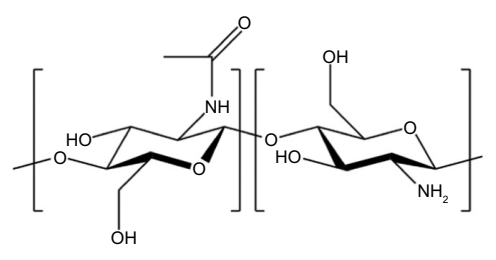

Chitosan

C Synthetic polymers<smiles>CC(C)(C)OC(=O)C(C)(C)C</smiles>

PLA<smiles>[R]C(C)(C)C(=O)NNPC(=O)C(C)(C)C</smiles>

PU<smiles>CCC(CC(=O)OC(C)CC(C)=O)OC(C)(C)C</smiles>

PHBV

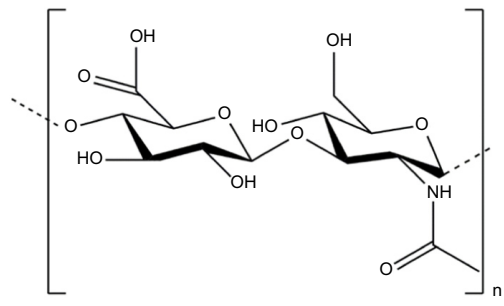

Hyaluronic acid<smiles>CC(C)(C)CCCCC(=O)OC(C)(C)C</smiles>

PCL<smiles>CC(C)(C)CC(O)C(C)(C)C</smiles>

PVA

Figure 5 Biological and synthetic polymers used in the structure of nerve conduits. Note: (A) Polyhydroxyalkanoates, (B) polysaccharides, (C) Synthetic polymers.

Abbreviations: P3HB, poly(3-hydroxybutyrate); PCL, poly(E-caprolactone); PGA, poly(glycolic acid); PHBV, poly(3-hydroxybutyrate-co-3-hydroxyvalerate); PLA, poly(lactic acid); PU, polyurethane; PVA, polyvinyl alcohol. 
and glial growth factor together, were used to bridge gaps 2-4 cm long in a rabbit common peroneal nerve model. PHB conduits served as a support in nerve regeneration for up to 63 days, bridging a $2 \mathrm{~cm}$ gap of axons. In another study, P3HB sheets together with a fibrin matrix were used to form a nerve conduit around an intravenous cannula. ${ }^{50}$ These constructs seeded with adipose-derived stem cells (ADSCs) showed regenerative capacity. The regenerative role of the transplanted ADSCs was explained to be through the released growth factors and/or by the activity of the endogenous Schwann cells. In a more recent study, Masaeli et $\mathrm{al}^{51}$ fabricated electrospun scaffolds by blending P3HB and $\mathrm{PHBV}$ in different proportions in order to investigate their potential for the regeneration of the myelinic membrane. Schwann cells grown on parallel PHB/PHBV/collagen fibers exhibited a bipolar morphology along the fiber direction, while Schwann cells grown on randomly oriented fibers had a multipolar morphology. It was concluded that aligned PHB/PHBV electrospun nanofibers could find potential use as scaffolds in nerve tissue engineering applications and presence of type I collagen in the nanofibers improves cell differentiation.

\section{PHBV}

Copolymers of 3-hydroxybutyrate and 3-hydroxyvalerate are the most widely used PHBV polymers due to our ability to tailor their physical characteristics according to our needs and their processability (Figure 5A). Incorporation of 3-hydroxyvalerate into the polymer chains leads to an increase in chain flexibility, and to a decrease in both the glass transition temperature and the melting temperature. This also improves the processability of the polymer. These properties make these polymers very suitable for use in nerve regeneration studies along with other tissue engineering applications. For example, a nanofibrous PHBV tube carrying Schwann cells was used as an artificial nerve graft for a $30 \mathrm{~mm}$ gap in a rat sciatic nerve model. ${ }^{52}$ This polymeric conduit had sufficiently high mechanical properties to serve as a nerve guide. The results demonstrated that the sciatic nerve trunk had been reconstructed with restoration of nerve continuity and formatted nerve fibers with myelination.

Chitosan crosslinked nanofibrous PHBV nerve guides produced by electrospinning were tested in a rat sciatic nerve regeneration model across a $10 \mathrm{~mm}$ gap defect. ${ }^{53}$ Prabhakaran et $\mathrm{al}^{54}$ fabricated random and aligned nanofibers of PHBV and composite PHBV/collagen nanofibers. The diameters of the PHBV and composite fibers were in the range 386-472 nm and $205-266 \mathrm{~nm}$, respectively. Aligned nanofibers of the composite showed contact guidance that led to the orientation of nerve cells along the direction of the fibers. This resulted in elongated cell morphology, with bipolar neurite extensions which were required for nerve regeneration.

\section{Proteins}

Scaffolds constructed of ECM proteins (collagen, fibrin, fibronectin, and hyaluronic acid) and using neurotropic factors have been extensively studied for peripheral nerve regeneration. In the preparation of nerve conduits, ECM proteins and other types of proteins like silk fibroin have been used alone or in combination with each other for more than 3 decades. Some of these studies involving various proteins are summarized below.

\section{Collagen}

Collagens are a family of 26 proteins, have a triple helical structure in the form of an extended rod, and they are the major components of the ECM. They have a high content of proline and hydroxyproline, and also a glycine at every third position. ${ }^{55}$ Collagen, mainly type I, constitutes approximately $30 \%$ of the mammalian musculoskeletal tissues, and is one of the oldest natural polymers to be used as a biomaterial. Collagens exist as fibrils in the endoneurium or as the non-fibrillar component of the basal lamina and are appropriate materials to be used as the nerve conduits. ${ }^{56}$ Fibrous constructs, hydrogels, particles, and foams are the different three-dimensional (3D) structures that can be produced from collagen Type $1 .{ }^{57}$ Acid soluble collagen has been used to produce a hydrogel scaffold which was a very low density $3 \mathrm{D}$ lattice of nanofibrils produced by a combination of compression and blotting using layers of mesh and paper sheets. ${ }^{58}$ The production method was used to obtain fibrils by unconfined plastic compression of hyperhydrated collagen gels. These scaffolds composed of aligned nanofibrils would have a significant potential for use in the regeneration of organized tissues like peripheral nerves. In a recent study, hydrogels of collagen Type 1 were used as the starting material, and after plastic compression, fibrillar collagen sheets, which were then rolled into 3D nerve conduits were formed.

There are a number of FDA-approved collagen-based materials to be used as nerve grafts such as NeuraGen ${ }^{\circledR}$, NeuroFlex $^{\mathrm{TM}}$, NeuroMatrix ${ }^{\mathrm{TM}}$, NeuraWrap ${ }^{\mathrm{TM}}$, and NeuroMend $^{\mathrm{TM}}$. Table 1 summarizes the FDA-approved nerve conduits. The first Type 1 collagen nerve guide conduit approved by the FDA, in 2001, was NeuraGen (Integra LifeSciences Co, Plainsboro, NJ, USA). Manufacturing process of these nerve conduits includes the preservation of the natural 
Table I Commercially available FDA-approved nerve conduits

\begin{tabular}{|c|c|c|c|}
\hline Product name & Material & Structure & Company \\
\hline NeuraGen $^{\circledR}$ & Collagen Type I & $\begin{array}{l}\text { Semipermeable, fibrillar structure } \\
\text { of the collagen }\end{array}$ & $\begin{array}{l}\text { Integra LifeSciences Co, Plainsboro, } \\
\text { NJ, USA }\end{array}$ \\
\hline NeuroFlex ${ }^{\mathrm{TM}}$ & Collagen Type I & $\begin{array}{l}\text { Flexible, semipermeable tubular } \\
\text { collagen matrix }\end{array}$ & $\begin{array}{l}\text { Collagen Matrix, Inc., Franklin } \\
\text { Lakes, NJ, USA }\end{array}$ \\
\hline NeuroMatrix ${ }^{\mathrm{TM}}$ & Collagen Type I & Semipermeable tubular collagen matrix & Collagen Matrix, Inc. \\
\hline NeuraWrap ${ }^{\mathrm{TM}}$ & Collagen Type I & Longitudinal slit in the tubular wall structure & Integra LifeSciences Co \\
\hline NeuroMend ${ }^{\mathrm{TM}}$ & Collagen Type I & $\begin{array}{l}\text { Semipermeable collagen wrap } \\
\text { designed to unroll and self-curl }\end{array}$ & Collagen Matrix, Inc. \\
\hline Neurotube $^{\circledR}$ & Polyglycolic acid & Absorbable woven PGA Mesh Tube & $\begin{array}{l}\text { Synovis Micro Companies } \\
\text { Alliance, Birmingham, AL, USA }\end{array}$ \\
\hline Neurolac $^{\mathrm{TM}}$ & $\begin{array}{l}\text { Poly }(\mathrm{D}, \mathrm{L} \text {-lactide- } \\
\text { co- } \varepsilon \text {-caprolactone })\end{array}$ & $\begin{array}{l}\text { Synthetic and transparent } \\
\text { PLCL tubular structure }\end{array}$ & $\begin{array}{l}\text { Polyganics BV, Groningen, } \\
\text { Netherlands }\end{array}$ \\
\hline Salutunnel ${ }^{\mathrm{TM}}$ & Polyvinyl alcohol & Non-biodegradable PVA tubular structure & Salumedica LCC, Atlanta, GA, USA \\
\hline
\end{tabular}

Abbreviations: FDA, Food and Drug Administration; PGA, poly(glycolic acid); PVA, polyvinyl alcohol; PLCL, poly(E-caprolactone-co-lactide).

fibrillar structure of the collagen and construction of a tubular matrix from those fibrillar sheets. ${ }^{59,60}$ The first trials on the efficacy of NeuraGen ${ }^{\circledR}$ were performed by Mackinnon et al ${ }^{60}$ who observed the absence of compression neuropathy, which was generally seen with more rigid materials. Similar trials made by Archibald et al ${ }^{59}$ using NeuraGen ${ }^{\circledR}$ entubulation approach showed repair of peripheral nerves in 4 weeks.

Two different collagen Type 1 nerve guidance conduit devices, NeuroMatrix ${ }^{\mathrm{TM}}$ and Neuroflex ${ }^{\mathrm{TM}}$ (Collagen Matrix, Inc., Franklin Lakes, NJ, USA), received FDA approvals in 2001. Both conduits are resorbable, flexible, non-friable, semipermeable tubular matrices with a pore size in the range $0.1-0.5 \mu \mathrm{m}$ to allow for nutrient transfer. Both conduits are resorbed in vivo within 4-8 months. The only difference between the two conduits is that NeuroMatrix ${ }^{\mathrm{TM}}$ does not have the kink resistant property of Neuroflex ${ }^{\mathrm{TM}}$. Both devices, however, were designed to be used in nerve-gap defects shorter than $2.5 \mathrm{~cm} .{ }^{61}$ The other Type 1 collagen based nerve conduit is NeuraWrap ${ }^{\mathrm{TM}}$ (Integra LifeSciences Co) having the same composition with NeuraGen ${ }^{\circledR}$. It received FDA approval in 2004. NeuraWrap ${ }^{\mathrm{TM}}$ was designed to prevent neuromas during regeneration and to be used by wrapping around the injured nerves. The wall structure of the device consists of a longitudinal slit. According to the manufacturers, the advantages of the device are 1) minimal scar formation because the porous outer membrane mechanically resists compression by surrounding tissues, 2) minimal encapsulation and nerve entrapment, and 3) the ability to create an environment suitable for regeneration as a result of the semipermeable inner membrane allowing nutrient transport. ${ }^{62}$

NeuroMend $^{\mathrm{TM}}$ (Collagen Matrix, Inc.) is a recent device composed of Type 1 collagen, having the same structure as the others, and was approved by the FDA in 2006. Although NeuroMend ${ }^{\mathrm{TM}}$ is a semipermeable, collagen-based wrap, it was designed to be unrolled and self-curled to best match the dimensions of the injured tissue.$^{63}$ Moreover, the semipermeable membrane allows diffusion of the nutrients while preventing the migration of fibroblasts and inflammation. ${ }^{64,65}$

The approved Type 1 collagen devices are used in the clinics. Research on pure or blended collagen devices, however, is continuing. Collagen nerve conduits releasing neurotrophic factors, such as glial cell-derived neurotrophic factor (GDNF) and NGF, were prepared by electrospinning using the spinning mandrel approach ${ }^{66}$ In this study, delivery of synergistically acting GDNF and NGF from the collagen nerve conduit resulted in a more successful repair of peripheral nerve defects compared with commercial products NeuraGen ${ }^{\circledR}$ and Neurolac ${ }^{\circledR}$. Yang and Chen ${ }^{67}$ investigated composite scaffolds prepared by blending and crosslinking chitosan with collagen and icariin. These scaffolds proved to be suitable cell carriers for use in nerve regeneration applications. More recently, micropatterned tubular collagen matrices produced by spin casting were reported to have a regenerative capacity when used in a rat sciatic nerve model. ${ }^{68}$

\section{Gelatin}

Gelatin, is denatured collagen, and has been widely used in tissue engineering applications after crosslinking with various chemicals. ${ }^{69}$ Genipin is a crosslinking agent with low cytotoxicity. ${ }^{70}$ Gamez et al ${ }^{71}$ prepared photofabricated, gelatinbased nerve conduits and implanted them between the proximal and distal stumps of a $10 \mathrm{~mm}$ dissected right sciatic nerve of adult male Lewis rats for up to 1 year. As a result, functional, morphological, and electrophysiological response recovery were observed. In another study, genipin crosslinked gelatin conduits were evaluated as a guidance channel for peripheral nerve regeneration, and the successful functional recovery of a $10 \mathrm{~mm}$ gap was tested in a rat sciatic model. ${ }^{72} \mathrm{Liu}^{73}$ fabricated a 
proanthocyanidin crosslinked gelatin conduit with a rough outer surface. The conduit was used in the regeneration of a $10 \mathrm{~mm}$ gap in a rat sciatic model, and regenerated nerve fibers crossing through and beyond the gap region were shown in 8 weeks. Nie et $\mathrm{al}^{74}$ tested gelatin- and chitosan-based nerve conduits with transforming growth factor $\beta 1$ in a $10 \mathrm{~mm}$ gap in the sciatic nerve of rats. After the implantation, the inner surface of the conduits remained intact during the regeneration time; thus, it could prevent the ingrowth of connective tissues. Functional recovery, electrophysiological test, retrograde labeling, and immunohistochemistry analysis showed similar nerve conduction velocity, regenerated myelin area, and myelinated axon count with those treated with an autograft.

\section{Fibronectin}

Fibronectin, one of the major ECM proteins, is a disulfidelinked glycoprotein. It has important roles in cell adhesion, morphology, migration, and differentiation, and interacts with collagen, heparin, fibrin, and cell surface receptors. ${ }^{75}$ In the early 1990s, guides produced from fibronectin under unidirectional shear were seen to lead to the orientation of cells along fibronectin pattern. ${ }^{76,77}$ Fibronectin was also used as a source for the release of supportive materials in nerve guidance conduits. ${ }^{75}$ In addition, the oriented strands of the cell adhesive fibronectin were prepared and used to bridge a $10 \mathrm{~mm}$ defect in the rat sciatic nerve. It was concluded that the oriented fibronectin was a material suitable for successful nerve repair and has potential for use in the clinics. In the 2000s, it was shown that fibronectin mats are successful guidance substrates for the outgrowth of neurites in injured rat sciatic nerve. ${ }^{78}$ Addition of fibronectin to alginate matrices was shown to improve peripheral nerve regeneration in tissue engineered conduits. ${ }^{79}$ Moshahebi et al studied how the addition of fibronectin to alginate would affect the outcome of nerve regeneration and showed that the presence of fibronectin supported Schwann cell viability and augmented its effect on axonal growth. Ding et $\mathrm{al}^{80}$ reported that coating the collagen scaffold with laminin and fibronectin increased its effectiveness in axon regeneration when tested 40 days after surgery for functional properties, using recovery electrophysiology and sciatic nerve functional index evaluation.

\section{Silk fibroin}

Silk is made of fibrous proteins synthesized by members of the class Arachnida and in the specialized epithelial cells that line the glands in worms of mites, butterflies, and moths. Silk fibroin is composed of repetitive protein sequences. ${ }^{81}$ It has hydrophobic domains of short side chain amino acids, and therefore, the general structure of silk fibroin is in the form of $\beta$-sheets. The assembly of silk and its strength originate from these hydrophobic regions interspaced with small hydrophilic segments. ${ }^{82}$ When compared with other protein-based biomaterials, there are many advantages of using silk such as the risk of infection and possibility of rejection of the other materials. Another significant advantage is the high mechanical properties such as modulus, breaking strength, and elongation. Biocompatibility, water-based processing, and biodegradability are the other advantages of silk for it to be considered in tissue engineering applications. The supportive capacity of silk fibroin for dorsal root ganglia and Schwann cells was shown by Yang et al. ${ }^{83}$ A scaffold composed of fibroin and spider silk was shown to be a good material to bridge a gap of up to 13 mm within 12 weeks. $^{84}$ In 2013, Gu et al ${ }^{85}$ reported the use of scaffolds modified with ECM produced by Schwann cells. The conduit was prepared from chitosan and silk fibroin fibers and then seeded with Schwann cells for ECM deposition. The morphological and electrophysiological analyses indicated that regenerative outcomes achieved by the developed scaffold were similar to those obtained with an acellular nerve graft but superior to those prepared by a plain chitosan-silk fibroin scaffold. In a recent study, spider silk proteins were also recommended for use in nerve regeneration applications because they support cell proliferation and regeneration. ${ }^{86}$

\section{Keratin}

Keratin is a protein produced by keratinocytes. Cysteine in the structure is rich in sulfur, and it plays a role in the cohesion of the hair. ${ }^{87}$ The hair fibers are mainly made up of crosslinked keratins, and these crosslinks can be broken and the free keratin molecules could be used in the construction of biomaterials. ${ }^{88,89}$ Sierpinski et a ${ }^{90}$ oxidized keratin crosslinks to form hydrogels. These keratin hydrogel nerve conduits were compared with sensory nerve autografts, and it was concluded that the keratin-based biomaterials also had neuroinductive capacity. Lin et al ${ }^{88}$ filled a conduit with keratin gel and studied its performance in a rat $15 \mathrm{~mm}$ sciatic nerve defect model. They observed a high density of Schwann cells and axons. Recently, a human hair keratin hydrogel was used as nerve conduit luminal filler following a median nerve transection injury model in Macaca fascicularis primates. ${ }^{89}$ The results obtained after 12 months by electrophysiology showed that the keratin-based scaffolds were able to support nerve regeneration.

\section{Polysaccharides}

Polysaccharides are a class of biopolymers constituted by mono- or disaccharides and have roles in membranes and in 
intracellular communication; they also have roles in storage (Figure 5B). Differences in the monosaccharide composition, chain organization, and molecular weight determine their physical properties including solubility, gelation, and surface properties. Heparin and other polysaccharides are structurally similar. They are highly biocompatible which makes them useful in use in tissue engineering applications. ${ }^{91,92}$ Some of the most commonly used saccharides in nerve regeneration constructs are given below.

\section{Chitin and chitosan}

Chitin, a component of the cytoskeleton in the outer skeleton of insects and in the exoskeleton of crustaceans, is the main source of chitosan, and after starch, it is the second most abundant polysaccharide on earth. ${ }^{93}$ Chitosan is a linear polysaccharide composed of glucosamine and N-acetyl glucosamine units linked by $\beta(1-4)$ glycosidic bonds (Figure 5B). Chitosan is the deacetylated form of chitin and is soluble in slightly acidic medium. Chitosan-based scaffolds are attractive for tissue engineering applications because of their ability to form interconnected porous structures (sponges), their cationic nature, and reasonable level of mechanical properties. Zheng and Cui ${ }^{94}$ used chitosan conduits combined with bone marrow MSCs to promote peripheral nerve regeneration. They found that BMSCs could differentiate into neural stem cells (NSCs) in vivo in rats and they could bridge an $8 \mathrm{~mm}$ long gap upon differentiation. ${ }^{95}$ Haastert-Talini et $\mathrm{al}^{95}$ constructed chitosan tubes to regenerate $10 \mathrm{~mm}$ nerve defects in adult rats. The chitosan tubes could be made of chitosan with low, medium, or high degrees of deacetylation, and therefore, present different levels and rates of degradation and microenvironments for the regenerating nerve tissue. Chitosan tubes, however, suffered from certain limitations such as a high rate of degradation and low mechanical stability. In another study conducted with chitosan nanofibers for peripheral nerve repair, it was concluded that the nontoxic nature of the chitosan fibers is appealing for peripheral nerve regeneration applications. ${ }^{96}$ Hsu et $\mathrm{al}^{97}$ combined laminin-coated chitosan conduits and stem cells to bridge a $10 \mathrm{~mm}$ long gap in the sciatic nerve of Sprague Dawley rats. The rats implanted with the conduit carrying BMSCs showed the best results when judged by the extent of nerve regrowth, muscle mass of gastrocnemius, functional recovery, and tract tracing.

\section{Hyaluronic acid}

Hyaluronic acid is an immunoneutral polysaccharide that is ubiquitous in the human body, and it has been in clinical use for over 30 years (Figure 5B). ${ }^{98}$ Hyaluronic acid can be processed into many physical forms such as viscoelastic solutions, hydrogels, electrospun fibers, nonwoven meshes, macroporous and fibrillar sponges, flexible sheets, and nanoparticulates. Suri and Schmidt ${ }^{99}$ produced hydrogel constructs of hyaluronic acid, collagen, and laminin for neural tissue engineering. Encapsulation of Schwann cells in 3D hydrogel constructs did not affect cell viability, and cells were viable for 2 weeks in all hydrogel samples. They also revealed that in the co-culture of dissociated neurons with Schwann cells, neurons were able to extend neurites, and some neurites were observed to follow Schwann cells. A study conducted on chitosan-gelatin porous scaffolds containing hyaluronic acid and heparan sulfate fabricated via lyophilization showed that presence of both chemicals in the scaffolds significantly promoted adhesion of NSCs and progenitor cells and supported growth in a $3 \mathrm{D}$ environment for long durations. ${ }^{100}$

\section{Synthetic nerve conduits}

Biodegradable synthetic polymers are attractive alternatives to the natural origin biopolymers due to the following advantages: 1) some biodegradable synthetic polymers are biocompatible and they do not initiate any immunological responses, 2) their mechanical properties and degradation rates can be controlled by changing the process conditions and components without changing the bulk features of the polymer, and 3) they can be processed in various forms to enhance the tissue ingrowth. ${ }^{101}$ Over time, the material choice for nerve conduits shifted towards the use of more biocompatible synthetic polymers. Biodegradable polyesters, such as poly(lactic acid) (PLA), poly(glycolic acid) (PGA), poly(lactic acid-co-glycolic acid) (PLGA), poly( $\varepsilon$-caprolactone) (PCL), polyurethanes (PUs), trimethylene carbonate-co- $\varepsilon$-caprolactone, poly(D,L-lactideco- $\varepsilon$-caprolactone), and nonbiodegradable polymers such as methacrylate-based hydrogels, polystyrene, silicone, and poly(tetrafluoroethylene), were used as nerve conduit materials. In Figure 5C, the structure of some synthetic polymers are presented. Various fabrication techniques such as electrospinning, injection molding, photolithography, and extrusion were used in the processing of these materials.

\section{Polyesters}

Polyesters have an ester functional group in their main backbone. PLA, poly(L-lactic acid) (PLLA), PGA, PLGA, and PCL are polyesters most commonly used in the fabrication of nerve conduits. 


\section{PLA}

PLA can be made from lactic acid obtained from corn, sugar beet, or wheat, and is biocompatible (Figure 5C). PLA was used as a nerve conduit material in a number of studies. In one such study, a multilayer PLA nerve conduit was fabricated by microbraiding to obtain adequate mechanical strength at the injury site. ${ }^{102}$ In the applications on rats, successful regeneration through the gap was observed at 8 weeks after operation. In another study, a PLA nerve conduit was made by immersion precipitation to bridge a $20 \mathrm{~mm}$ long gap in a rabbit sciatic nerve transection model. ${ }^{103}$ These conduits had macropores on the outside, and interconnected micropores in the inner layer to provide a higher outflow rate than inflow rate. It was reported that the functional recovery after 18 months was about $80 \%$, based on electrophysiology and behavior analysis. A nonwoven fabric nerve conduit was made by a melt-blow process, in which the fabric was wrapped around a stainless steel core bar and heated at $90^{\circ} \mathrm{C}$ for 20 minutes. ${ }^{104}$ In this study, nerve conduits made of a PLA non-woven fabric, a silicone tube filled with type I collagen gel, and an autologous nerve were implanted in the buccal branch of a $7 \mathrm{~mm}$ facial nerve defect, and their nerve regeneration performances were evaluated 13 weeks after the surgery. The number of myelinated neural fibers in the middle portion of the regenerated nerve and the axon diameter were the highest for PLA tubes. It was concluded that PLA non-woven fabric tube, composed of randomly connected PLA fibers, provided better nerve regeneration compared with a silicone control. In a different study, alignment in a nerve conduit was provided with microporousmicropatterned PLA by photolithography. ${ }^{105}$ PLA conduits grafted with chitosan-nano $\mathrm{Au}$ and the fibroblast growth factor 1 (FGF1) after plasma activation showed the greatest regeneration capacity and functional recovery when they were tested for their ability to bridge a $15 \mathrm{~mm}$ critical gap defect in a rat sciatic nerve injury model. Addition of NSCs on the micropatterned surfaces further enhanced efficacy of the conduits compared with autografts.

\section{PLLA}

PLLA is a stereoregular and highly crystalline form of PLA. It is also widely used in tissue engineering applications. In a study, a PLLA nerve conduit was fabricated by extrusion and was used in a $10 \mathrm{~mm}$ sciatic nerve defect model in rats. ${ }^{106}$ The PLLA conduits were highly porous with an interconnected pore structure ( $83.5 \%$ porosity and $12.1 \mu \mathrm{m}$ mean pore size). The nerve fiber density in the distal sciatic nerve for the PLLA conduits was similar to that for the control isografts at 16 weeks. Increased axon number and nerve fiber density was found in the PLLA mid-conduit compared with control isograft at 16 weeks. In more recent years, importance of the alignment in nerve guide conduits was understood, and the designers of the conduits started to take this into account. In a later study, a porous, micropatterned poly(D,L-lactic acid) (PDLLA) conduit was seeded with Schwann cells to provide additional trophic and physical support in a $10 \mathrm{~mm}$ rat sciatic nerve defect. ${ }^{107}$ The results showed that time of recovery and the sciatic function indices were significantly enhanced when the Schwann cell-seeded conduits were used, and it was concluded that biodegradable, micropatterned conduits seeded with Schwann cells which provide a combination of physical, chemical, and biological guidance cues for regenerating axons at the cellular level offered a better alternative in the repair of sciatic nerve compared with conventional biodegradable conduits. Li et al ${ }^{108}$ prepared multi-walled PLLA conduits using solvent casting, physical imprinting, and rolling-fusing methods to obtain multiple intraluminal walls and precise topography along the longitudinal axis to provide the alignment along the conduits. It was demonstrated that when cultured on these patterned films, PC12 cells and chick sympathetic neurites aligned predominantly in the direction of the underlying grooves.

In recent years, besides photolithographic techniques, electrospinning has become a powerful technique to create aligned structures needed to improve the growth of the neurons within the conduits. To illustrate, PLLA was combined with polycaprolactone and NGF to promote neurite outgrowth using core-shell structured biodegradable nanofibers fabricated by coaxial electrospinning. ${ }^{109}$ Here, poly(L-lactide-co$\varepsilon$-caprolactone) (P(LLA-CL)) was used for the shell, and bovine serum albumin (BSA) or BSA/NGF for the core, and implanted at a $10 \mathrm{~mm}$ long rat sciatic nerve defect. The functional and histological observations revealed that the number and arrangement of regenerated nerve fibers, myelination, and restoration of nerve function in the $\mathrm{P}$ (LLA-CL)/NGF conduit group and the nerve autograft group were similar, but they were significantly greater than the empty P(LLA-CL) or the NGF-injected P(LLA-CL) conduit groups. It was, therefore, concluded that incorporation of NGF in the nerve conduit had a positive contribution on both myelination and functional recovery of the nerves. In addition to the contribution of alignment in the conduits, conductivity is another parameter in obtaining physiologically active, properly healed nerves. In a recent study, PDLLA was blended with polypyrrole (PPy) to produce a conducting nerve conduit. ${ }^{110}$ Increasing degrees of conductivity $(5.65,10.40$, and $15.56 \mathrm{mS} / \mathrm{cm})$ were obtained with increasing PPy content $(5 \%, 10 \%$, and 
$15 \%$, respectively). It was found that there was a significant increase in both the percentage of neurite bearing cells and the median neurite length as the PPy content was increased when PC12 cells, seeded on these conduits, were stimulated with $100 \mathrm{mV}$ for 2 hours. It was reported that the PPy/PDLLA nerve conduit performed similarly to the "gold standard" autologous nerve graft in the repair of a $10 \mathrm{~mm}$ rat sciatic nerve defect.

\section{PGA}

PGA is another biodegradable, rigid, thermoplastic, and highly crystalline polyester which exhibits a high tensile modulus with very low solubility in organic solvents (Figure 5C). ${ }^{111}$ In an earlier study, PGA-based crimped tube device (Neurotube ${ }^{\circledR}$; Synovis Micro Companies Alliance, Birmingham, AL, USA) was described for the repair of peripheral nerve injuries. ${ }^{112}$ It is the first synthetic, highly porous, bioresorbable nerve guide conduit to receive approval by the FDA (1999). In a more recent study, bone marrow stem cells (BMSCs) were combined with PGA tube (PGAt) $\left(\right.$ Neurotube $\left.^{\mathbb{R}}\right)$ in autografted rat facial nerves. ${ }^{113}$ After cutting of the mandibular branch of the rat facial nerve, surgical repair consisted of autologous graft in a PGAt filled with basement membrane matrix with undifferentiated BMSCs or Schwann-like cells that had differentiated from BMSCs. After 6 weeks of surgery, animals from either cell-containing group had compound muscle action potential amplitudes significantly higher than the control groups. Facial nerves with Schwann-like cell implants had axonal densities within the range of reference values, and had the highest axonal diameter in distal segments. It was concluded that regeneration of the facial nerve was improved by BMSCs within PGAt in rats; however, Schwann-like cells yielded superior effects. PGA is also commonly combined with natural polymers such as collagen (will be explained in the "Hybrid nerve conduits" section).

\section{PLGA}

PLGA is a copolyester that has been used extensively as a nerve guide material due to its ease of fabrication, approval by the FDA, and low inflammatory response it created. In an earlier study, porous, PLGA conduits with longitudinally aligned channels were produced by using a combined injection molding and thermally induced phase transition technique. ${ }^{114}$ In this approach, PLGA, dissolved in acetic acid, was injected into a cold mold which induced solidification of the polymer solution and led to solid-liquid phase separation. The foam obtained had a macrostructure with high anisotropy due to the removal of acetic acid by sublimation. Macropores were organized into bundles of channels up to $20 \mu \mathrm{m}$ wide in the PLGA matrix, which then was used as a nerve conduit. In another study, NGF was incorporated into the PLGA nerve conduits (single or multiple lumens) which were fabricated from a mixture of PLGA microspheres and porogen $(\mathrm{NaCl})$ that was loaded into a mold and processed by gas foaming. ${ }^{115}$ After 13 days of implantation, the conduits were observed to have sufficient mechanical properties, which could be controlled by porosity. Porosity was needed to create open channels that allow tissue ingrowth. It was concluded that PLGA conduits with controllable lumen diameters and protein release might enhance nerve regeneration by guiding and stimulating neurite outgrowth. Wen and Tresco ${ }^{116}$ fabricated PLGA hollow fiber membranes (HFMs) using a wet phase inversion technique to create nerve tract guidance channels. HFMs with different size, inner and outer surface morphologies, porosity, and permeability were produced and under simulated in vitro physiological conditions, PLGA HFMs exhibited a degradation profile to accommodate nervous system regeneration and axonal outgrowth. In another study, PLGA was combined with pluronic F127, which is a nonionic, surfactant polyol. ${ }^{117}$ Asymmetrically porous PLGA-F127 tubes were produced to serve as nerve guide conduit using a modified immersion-precipitation method. By making the scaffold asymmetric, the inner surface of the tube with nanosize pores $(\sim 50 \mathrm{~nm})$ could effectively prevent fibrous tissue infiltration but allow permeation of nutrients and retain neurotrophic factors. Meanwhile, the outer surface had microsize pores $(\sim 50 \mu \mathrm{m})$ that could allow vascular ingrowth to supply nutrients inside the tube. It was reported that after implantation into a $10 \mathrm{~mm}$ left sciatic nerve defect in rats, immunohistochemical and electrophysiological evaluations showed that PLGA-F127 tubes were better in nerve regeneration than the control silicone or hydrophobic PLGA tubes. In another study, PPy-coated, electrically conductive, electrospun PLGA nanofibers were fabricated to investigate the combined effect of nanofiber structures and electrical stimulation. ${ }^{118}$ PPy-PLGA electrospun meshes enhanced the growth and differentiation of rat PC12 cells and hippocampal neurons. Electrical stimulation showed that PC12 cells stimulated on PPy-PLGA scaffolds exhibited 40\%-50\% longer neurites and 40\%-90\% more neurite formation compared with unstimulated cells on the same scaffolds. In addition, stimulation of the cells on aligned PPy-PLGA fibers resulted in longer neurites and more neurite-bearing cells than stimulation on random PPy-PLGA fibers. As expected, combined effect of electrical stimulation and topographical 
guidance provided better nerve guide conduits. In another study, PLGA nerve conduits, made of cylindrically woven PLGA filaments, were treated with pulsed oxygen plasma and coated with ciliary neurotrophic factor (CNTF) and chitosan, and were used in the repair of $25 \mathrm{~mm}$ long canine tibial nerve defects in crossbred dogs. ${ }^{119}$ After 3 months, histological results showed that PLGA/chitosan-CNTF conduits were better than the PLGA/chitosan conduits, and were similar to autologous nerve grafts. In a recent study, nerve tubes of PLGA, poly(caprolactone-fumarate) (PCLF), a neutral oligo[(polyethylene glycol) fumarate] hydrogel and a positively charged oligo[(polyethylene glycol)fumarate] hydrogel with a PCLF sleeve, were implanted in a rat sciatic nerve model. ${ }^{120}$ The PCLF tube significantly improved nerve regeneration and recovery compared with the other conduits.

\section{PCL}

PCL another polyester, has high solubility in organic solvents, low melting temperature $\left(55^{\circ} \mathrm{C}-60^{\circ} \mathrm{C}\right)$ and glass transition temperatures $\left(-60^{\circ} \mathrm{C}\right)$ (Figure $\left.5 \mathrm{C}\right)$. When its in vivo performance was compared with those of PHB conduits, PCL conduits were better in bridging up a $10 \mathrm{~mm}$ gap in rat sciatic nerve in 2 weeks. ${ }^{121}$ Oliveira et al ${ }^{122}$ incorporated MSCs into a PCL nerve conduit to improve median nerve regeneration after transection. MSC-treated animals showed significantly larger numbers of myelinated and unmyelinated nerve fibers and blood vessels compared with DMEM (Dulbecco's Modified Eagle's medium)-treated animals. This system also prevented decrease of creatine phosphokinase levels, which might be an indicator of tissue activity in muscle, and improved functional recovery in mice. In one study, PCLF was blended with a conductive polymer, PPy, and electrical stimulation was applied. ${ }^{123}$ In vitro studies with PC12 cells showed that there was a significant increase in the percentage of neurite bearing cells, number of neurites per cell, and neurite length when electrical stimulation was applied. Extending neurites were observed to align in the direction of the current applied. In another study, controlled release of vascular endothelial growth factor (VEGF) from PCLF nerve conduits was studied. ${ }^{124}$ VEGF was added into PLGA microspheres by double emulsion solvent evaporation technique, placed in the PCLF guide, and robust angiogenesis and nerve regeneration were observed. Another group filled biodegradable PCL tubes with MSCs and used these tubes in the treatment of the left sciatic nerve of mice. ${ }^{125}$ There was a significant increase in the number of myelinated fibers and the number of neurons in the dorsal root ganglion for the
PCL conduits with MSCs. Higher values of trophic factor expression, especially that of NGF, and improvement in the sciatic functional index were observed in the MSC-treated groups. Moreover, there was an increase in the weight of the gastrocnemius muscle and creatine phosphokinase enzyme, suggesting an improvement of reinnervation and activity in animals that received MSCs.

Effect of the type of surface topography and mechanical properties on cell morphology and alignment were investigated by using smooth, pitted, and grooved structures of ultrathin PCL-PLA solvent cast films. ${ }^{126}$ The PCL-PLA conduits were made by rolling the films around a mandrel and using a thermal welding technique to join the edges. It was concluded that sloped channels and their angles were the most important parameters in guiding nerve cell arrangement. Besides, the grooved structure reduced the mechanical strength of PCL-PLA films, so the mechanical properties became closer to those of the healthy nerve.

Dual stimulation, with NGF acting as a biological stimulus and low intensity pulse ultrasound (US) as a physical stimulus, was applied to enhance nerve regeneration within asymmetrically porous PCL-pluronic F127 conduits. ${ }^{127}$ These conduits were implanted into a $10 \mathrm{~mm}$ left sciatic nerve defect in rats. After 12 and 24 weeks of implantation, it was reported that each stimulation (NGF or US) had a positive effect in promoting the peripheral nerve regeneration through the nerve guide conduit. However, the US-stimulated nerve guide conduit group achieved faster nerve regeneration compared with the NGF-stimulated group. Dual stimulation (NGF and US) was more effective on nerve regeneration than the single stimulation.

\section{Poly(D,L-lactide-co- $\varepsilon$-caprolactone)}

Poly(D,L-lactide-co- $\varepsilon$-caprolactone) is a copolymer of lactic acid and caprolactone monomers. In a study, cylindrical poly(D,L-lactide-co- $\varepsilon$-caprolactone) $80 / 20$ copolymer nerve conduits were fabricated by using an ink-jet system. ${ }^{128}$ In Radulescu et al's previous study, it was found that hNGFEcR-293 cells could be genetically modified to deliver NGF in vitro and in vivo to support the local neuroreparative factor delivery via a tightly controlled system. ${ }^{129}$ Their findings demonstrated that these cells could attach and survive for more than 8 weeks when cultured on the 80/20 PLA-PCL copolymer but failed to attach and died on 25/75 and 40/60 PLAPCL copolymer used. The level of bioactive NGF was higher compared with control on 80/20 PLA-PCL scaffolds.

In another study, Neurolac ${ }^{\mathrm{TM}}$, a commercial poly(D,Llactide-co- $\varepsilon$-caprolactone) nerve guide, was used on patients. ${ }^{130}$ 
Neurolac ${ }^{\mathrm{TM}}$ was tested on 28 nerve lesions on various sites: arm, elbow, forearm, wrist, palm, and fingers. Defects were about $11 \mathrm{~mm}$ long. After an average of 21.9 months follow-up (3-45 months), subjective criteria (pain and cold intolerance) and objective criteria (strength) were compared with the contralateral side. Average pain score was 2.17/10, and cold intolerance was reported in 15 cases. Grip strength averaged $64.62 \%$ of the contralateral side. Eight complications were observed, the most serious being two fistulizations of the Neurolac $^{\mathrm{TM}}$ device close to a joint and one neuroma. It was concluded that use of Neurolac ${ }^{\mathrm{TM}}$ in repairing hand nerve defects was not very effective.

\section{PUs}

PU is a polymer with a backbone containing urethane linkages and is used in the fabrication of many biomedical devices including the nerve guides (Figure 5C). PU conduits prepared by uniform coating on a rotating mandrel were implanted for the repair of a $12 \mathrm{~mm}$ femoral nerve-gap model in rabbits, and myelinated axon regeneration was observed after 4 weeks of implantation. ${ }^{131}$ In a more recent study, nerve guides were prepared from block PUs (abbreviated as PUCL-ran-EG) which were based on poly(3-caprolactone) (PCL-diol) and poly(ethylene glycol), without any additional compounds like growth factors or proteins, by using particle leaching method. ${ }^{132}$ They had pore sizes in the range $1-5 \mu \mathrm{m}$ and porosity $88 \%$. Four types of guides, PUCL-ran-EG, autograft, PCL, and silicone tubes, were compared in the rat model. Bridging of a $10 \mathrm{~mm}$ defect gap by the regenerated nerve was observed in all rats after 14 weeks. Results revealed that polyurethane nerve guides exhibited much better regeneration behavior than the others and were comparable to the autograft.

\section{Polyols}

Polyvinyl alcohol (PVA) is a water soluble, nondegradable, synthetic polymer and was used as a nerve conduit material in addition to its many other uses in the biomedical field (Figure 5C). Currently there is a commercially available nonresorbable PVA hydrogel (SaluBridge; SaluTunnel; SaluMedica LCC, Atlanta, GA, USA). In a study, a tubular PVA conduit was produced by using a single screw extruder, and preseeded with Schwann cells. ${ }^{133}$ Porosity, wall thickness, and the Schwann cell seeding density were tested for their effect on axon growth using rat dorsal root ganglia. It was found that high wall thickness and low porosity have a detrimental effect on the growth of the axons. Maximum growth rate was observed at a porosity of $75 \%$ for Schwann cell-seeded conduits, but not with unseeded ones. In more recent studies, ${ }^{134,135}$ PVA was combined with chitosan. (This will be further explained in the "Polysaccharides with synthetic biomaterials" section).

\section{Hybrid nerve conduits}

The surface characteristics and charge densities of the nerve conduits have an important role in cell adhesion. ${ }^{136,137}$ Most of the synthetic materials used for this purpose are hydrophobic and they are not very suitable for cell adhesion. As a result, researchers started to coat the guide surfaces with ECM proteins or design hybrid nerve conduits with different architectures to overcome this problem. ${ }^{138-143}$ In recent years, use of such hybrids in nerve guide production has increased due to the improved properties achieved as a result of using a combination of natural and synthetic polymers. Some of those studies are summarized below.

\section{Polyesters with synthetic biomaterials}

Biological polyesters like PHBV can be combined with synthetic polymers. Yucel et al ${ }^{144}$ constructed a biodegradable, tubular nerve conduit by wrapping a porous micropatterned film (PHBV-P(L-D,L)LA-PLGA) around aligned electrospun fibers (PHBV-PLGA). It was revealed that this two-component nerve conduit would have a good potential to serve as a nerve guide with its porosity and mechanical properties. The polymer blends were chosen so that the protective tube cover, film part, would erode slower than the fibrous mat to achieve complete healing before the tube eroded. Characterization with scanning electron microscopy showed that the fibers were aligned parallel to the groove axis of the micropatterned films, making the conduit desirable for peripheral nerve regeneration applications with its oriented architecture. In further studies, Yucel et al ${ }^{145}$ constructed a guided tissue engineered nerve tube which consisted of aligned, electrospun fibers (PHBV-PLGA) seeded with NSCs wrapped in a porous, micropatterned film (PHBVP(L-D,L)LA-PLGA) with supportive cells aligned along the microgrooves to support the NSCs. The investigations of cell behavior on the scaffolds showed that both cells, undifferentiated NSCs, and supportive cells were oriented along the guiding and support elements, the microgrooves, and the aligned fibers. In addition, in vitro studies showed that the cells were able to survive and maintained their alignment in the $3 \mathrm{D}$ tissue engineered nerve tube.

\section{Polysaccharides with synthetic biomaterials}

Polysaccharides like chitosan are widely combined with synthetic polymers to prepare neural conduits. Cooper et al ${ }^{146}$ 
fabricated parallel chitosan-PCL fiber bundles or meshes for nerve tissue regeneration and investigated how the fiber orientation influenced nerve cell organization and function in comparison with randomly oriented fibrous scaffolds or cast films of the same material. Schwann cells grown on the parallel chitosan-PCL fibers exhibited a bipolar morphology that aligned with the fiber direction. The chitosan-PCL material supported neuron-like PC12 cell adhesion, and the parallel fibers regulated the growth of PC12 cells along the fiber orientation. In another study, chitosan-PVA nanofibers produced by electrospinning were combined with single-walled carbon nanotube (SWCNT), and results have shown that SWCNTs as reinforcing phase can augment the morphology, porosity, and structural properties of chitosan-PVA nanofiber composites and thus benefit the proliferation rate of both human brain-derived cells and astocytoma cells (U373). ${ }^{134}$

Table 2 Conduit materials used in the regeneration of the peripheral nerves and their success rates

\begin{tabular}{|c|c|c|c|c|c|}
\hline Conduit material and cells & Species & $\begin{array}{l}\text { Production } \\
\text { method/source }\end{array}$ & Defect size/site & $\begin{array}{l}\text { Regrowth } \\
\text { rate }\end{array}$ & Study \\
\hline $\mathrm{PHB}$ & Cat & Sheets & Superficial radial nerve & 12 months & Hazari et al $^{45}$ \\
\hline $\mathrm{PHB}$ & Human & - & $\begin{array}{l}\text { A complete median and/ } \\
\text { or ulnar nerve injury at } \\
\text { the wrist/forearm level }\end{array}$ & 18 months & Aberg et $\mathrm{al}^{46}$ \\
\hline PHB-glial growth factor & Rabbit & Compressed fiber sheets & $2-4 \mathrm{~cm}$ peroneal nerve & 2 months & Mohanna et $\mathrm{al}^{49}$ \\
\hline PHB/adipose derived stem cells & Sprague Dawley rat & Sheets & I cm sciatic nerve & 2 weeks & Erba et $\mathrm{al}^{50}$ \\
\hline PHBV/Schwann cells & Rat & Electrospinning & $30 \mathrm{~mm}$ sciatic nerve & 4 months & Biazar and Heidari ${ }^{52}$ \\
\hline Chitosan crosslinked PHBV & Rat & Electrospinning & $10 \mathrm{~mm}$ sciatic nerve & 4 months & Biazar and $\mathrm{Keshel}^{53}$ \\
\hline Gelatin & Lewis rat & Photofabrication & $10 \mathrm{~mm}$ sciatic nerve & I year & Gamez et $\mathrm{al}^{71}$ \\
\hline Gelatin & Rat & Genipin crosslinking & $10 \mathrm{~mm}$ sciatic nerve & 6 weeks & Chen et $\mathrm{al}^{72}$ \\
\hline Gelatin & Rat & $\begin{array}{l}\text { Proanthocyanidin } \\
\text { crosslinking }\end{array}$ & $10 \mathrm{~mm}$ sciatic nerve & 8 weeks & $\operatorname{Liu}^{73}$ \\
\hline Gelatin, TGF- $\beta$ I & Rat & - & $10 \mathrm{~mm}$ sciatic nerve & 16 weeks & Nie et $\mathrm{al}^{74}$ \\
\hline Fibronectin & Wistar rat & Air dry/from plasma & $5 \mathrm{~mm}$ interstump & 6 weeks & Phillips et $\mathrm{al}^{78}$ \\
\hline Fibronectin, collagen & Rat & - & $10 \mathrm{~mm}$ sciatic nerve & 40 days & Ding et $\mathrm{a}^{80}$ \\
\hline Silk & Wistar rat & Solvent casting & $8 \mathrm{~mm}$ sciatic nerve & 4 weeks & Huang et $\mathrm{al}^{84}$ \\
\hline Silk-chitosan & Rat & Degumming & $10 \mathrm{~mm}$ sciatic nerve & 12 weeks & Gu et $a^{85}$ \\
\hline Keratin filler & Rat & - & I 5 mm sciatic nerve & 6 weeks & Lin et $\mathrm{al}^{88}$ \\
\hline Keratin & Primate & Isolated from human hair & I cm median nerve & 12 months & Pace et $\mathrm{al}^{89}$ \\
\hline Chitosan/BMSC & Rat & Solvent casting & $8 \mathrm{~mm}$ sciatic nerve & 6 weeks & Zheng and Cui ${ }^{94}$ \\
\hline Chitosan & Rat & Extrusion & $10 \mathrm{~mm}$ sciatic nerve & 13 weeks & Haastert-Talini et al ${ }^{95}$ \\
\hline Chitosan/BMSC & Rat & Solvent casting & $10 \mathrm{~mm}$ sciatic nerve & 16 weeks & Hsu et $\mathrm{al}^{97}$ \\
\hline PLA & Rat & Microbraiding & $10 \mathrm{~mm}$ sciatic nerve & 8 weeks & Lu et al $^{102}$ \\
\hline PLA & Rabbit & Immersion precipitation & $20 \mathrm{~mm}$ sciatic nerve & 18 months & Hsu et $\mathrm{al}^{103}$ \\
\hline PLA & Rat & Melt-blow process & $7 \mathrm{~mm}$ facial nerve & 13 weeks & Matsumine et al ${ }^{104}$ \\
\hline PLA & Rat & Photolithography & I 5 mm sciatic nerve & 12 weeks & $\mathrm{Ni}$ et $\mathrm{al}^{105}$ \\
\hline PLLA & Rat & Extrusion & $10 \mathrm{~mm}$ sciatic nerve & 16 weeks & Evans et $\mathrm{al}^{106}$ \\
\hline PLLA & Rat & Reactive ion etching & $10 \mathrm{~mm}$ sciatic nerve & 8 weeks & Rutkowski et al ${ }^{107}$ \\
\hline PLLA, PCL & Rat & Coaxial electrospinning & $10 \mathrm{~mm}$ sciatic nerve & 12 weeks & Liu et $\mathrm{al}^{109}$ \\
\hline PLLA, PPy & Rat & Solvent casting & $10 \mathrm{~mm}$ sciatic nerve & 6 months & Xu et al ${ }^{110}$ \\
\hline PGA, collagen & Cat & Fiber mesh & $25 \mathrm{~mm}$ sciatic nerve & 5 months & Kiyotani et al ${ }^{147}$ \\
\hline PGA, collagen & Dog & - & $80 \mathrm{~mm}$ peroneal nerve & 3 months & Matsumato et al ${ }^{148}$ \\
\hline PLGA, FI27 & Rat & Immersion precipitation & $10 \mathrm{~mm}$ sciatic nerve & 4 weeks & Oh et $\mathrm{al}^{117}$ \\
\hline PLGA, chitosan-CNTF & Dog & Pulsed plasma & $25 \mathrm{~mm}$ tibial nerve & 3 months & Shen et $\mathrm{al}^{119}$ \\
\hline PCL/MSCs & Mice & - & $3 \mathrm{~mm}$ sciatic nerve & 6 weeks & Frattini et al $^{125}$ \\
\hline PCL, FI27 & Rat & Immersion precipitation & 10 mm sciatic nerve & 12 weeks & Kim et $\mathrm{al}^{127}$ \\
\hline PU & Rabbit & Rotating mandrel & $12 \mathrm{~mm}$ femoral nerve & 6 months & Yin et $\mathrm{al}^{|3|}$ \\
\hline PU & Rat & Dipping-leaching & 10 mm sciatic nerve & 14 weeks & Niu et $\mathrm{al}^{132}$ \\
\hline PGA, collagen & Cat & - & $25 \mathrm{~mm}$ sciatic nerve & 3 months & Kiyotani et al ${ }^{147}$ \\
\hline PGA, collagen & Dog & - & $80 \mathrm{~mm}$ peroneal nerve & 3 months & Matsumato et al ${ }^{148}$ \\
\hline PGA, collagen & Dog & Braiding & $15 \mathrm{~mm}$ peroneal nerve & 2 months & Nakamura et al ${ }^{150}$ \\
\hline PGA, collagen & Canine & Solvent casting & $80 \mathrm{~mm}$ peroneal nerve & 12 months & Toba et $\mathrm{al}^{149}$ \\
\hline
\end{tabular}

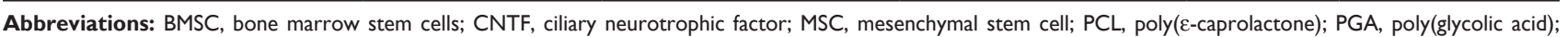
PHB, polyhydroxybutyrate; PHBV, poly(3-hydroxybutyrate-co-3-hydroxyvalerate); PLA, poly(lactic acid); PLGA, poly(lactic acid-co-glycolic acid); PLLA, poly(L-lactic acid); PPy, polypyrrole; PU, polyurethane; TGF, transforming growth factor. 
Alhosseini et al ${ }^{135}$ produced electrospun PVA-chitosan nanofibrous scaffolds with large pore sizes for nervous tissue repair. The chitosan-containing scaffolds were used for in vitro cell culture in contact with PC12 nerve cells, and it was found that addition of chitosan to the PVA scaffolds enhances viability and proliferation of nerve cells.

\section{Proteins with synthetic biomaterials}

Proteins are natural polymers, and therefore, their blends with synthetic polymers could be considered as hybrid structures. The most commonly used protein in hybrid preparation is collagen. In a study, a PGA fibrous mesh was coated with collagen, filled with neurotrophic factors, and implanted across a $25 \mathrm{~mm}$ long left sciatic nerve gap in cats. ${ }^{147}$ Regeneration of both myelinated and unmyelinated axons was confirmed by electron microscopy after 5 months of surgery. After 4-16 months of implantation, histology revealed the regeneration of well vascularized nerve tissue. Electrophysiological examinations demonstrated restoration of evoked electromyograms and sensory-evoked potentials, which were recorded from the cerebral cortex as well as from the spinal cord. In another study, PGA-collagen tubes filled with laminin-coated collagen fibers were implanted into an $80 \mathrm{~mm}$ gap in the left peroneal nerve of dogs. ${ }^{148}$ The outer tube was made of cylindrically woven PGA mesh; its outer and inner surfaces were coated with amorphous collagen coated with laminin. Histological observations showed that numerous unmyelinated and myelinated nerve fibers regrew through and beyond the gap after 12 months of implantation. Compound muscle action potentials, motor-evoked potentials, and somatosensory-evoked potentials gave peak amplitudes, and latencies were recovered gradually after 3 months of implantation, indicating the functional establishment of the nerve connection with the target organs. This sample was later compared with another guide, PGA-collagen tubes filled with laminin-soaked collagen sponges ${ }^{149}$ by implanting into $80 \mathrm{~mm}$ gaps of canine peroneal nerve defects. After 12 months, both morphometrically and electrophysiologically effective nerve regeneration was observed in the sponge group, although these differences were statistically insignificant. In another study, a PGA-collagen tube was implanted across a $15 \mathrm{~mm}$ gap in the left peroneal nerves of 24 beagle dogs. ${ }^{150}$ As a control, the right peroneal nerve was reconstructed with the autograft harvested from the left side. PGA tube was prepared with a tubular braiding machine, and it was coated with collagen layers. Results showed that the myelinated axons on the PGA side were larger in diameter than those on the autograft side. This PGA-collagen nerve conduit led to superior functional recovery in comparison to the autograft.

\section{Future perspectives and conclusion remarks}

As can be seen in this review, the nerve guide field is developing in a variety of directions such as the choice of different types of nerve and support cells (Schwann cells), use of fibers or channels for guidance, use of bioactive agents (mainly growth factors) to enhance the response of the seeded cells or the cells in the vicinity of the defect site, and the choice of polymers to be used as the guide material. The advances made are significant, as shown by the number of commercially available nerve guides. Table 2 summarizes the types and the performance of a variety of conduit materials. The limitation appears to be in the length of the defect that we can treat (which is not longer than $2 \mathrm{~cm}$ ) with our sophisticated materials and designs. The target should now be to increase the length of the defect that we can treat through the use of the current knowledge that has been accumulated mainly over the last decade.

\section{Disclosure}

The authors report no conflicts of interest in this work.

\section{References}

1. Daly W, Yao L, Zeugolis D, et al. A biomaterials approach to peripheral regeneration: bridging the peripheral nerve gap and enhancing functional recovery. $J$ R Soc Interface. 2012;9:202-221.

2. Seddon H. Three types of nerve injury. Brain. 1943;66:237-288.

3. Sunderland S. A classification of peripheral nerve injuries producing loss of function. Brain. 1951;74:491-516.

4. Campbell WW. Evaluation and management of peripheral nerve injury. Clin Neurophysiol. 2008;119:1951-1965.

5. Deumens R, Bozkurt A, Meek MF, et al. Repairing injured peripheral nerves: bridging the gap. Prog Neurobıol. 2010;92:245-276.

6. Millessi H. Techniques for nerve grafting. Hand Clin. 2000;16: 73-91.

7. Kehoe S, Zhang XF, Boyd D. FDA approved guidance conduits and wraps for peripheral nerve injury: a review of materials and efficacy. Injury. 2012;43:553-572.

8. Siemionow M, Brzezicki G. Chapter 8: current, techniques and concepts in peripheral nerve repair. In: Stefano G, Pierluigi T, Bruno B, editors. International Review of Neurobiology. San Diego, CA: Academic Press; 2009:141-172.

9. Nichols CM, Brenner MJ, Fox IK, et al. Effects of motor versus sensory nerve grafts on peripheral nerve regeneration. Exp Neurol. 2004;190:347-355.

10. Siemionow M, Sonmez E. Nerve Allograft transplantation: a review. J Reconstr Microsurg. 2007;23(8):511-520.

11. Hebebrand D, Zohman G, Jones NF. Nerve xenograft transplantation: immunosuppression with FK-506 and RS-61443. Biomaterials. 1997;22(3):304-307.

12. Jia HJ, Wang Y, Tong XJ, et al. Sciatic nerve repair by acellular nerve xenografts implanted with BMSCs in rats xenograft combined with BMSCs. Synapse. 2012;66:256-269. 
13. Mackinnon S, Hudson A, Falk R, Bilbao J, Kline D, Hunter D. Nerve allograft response: a quantitative immunological study. Neurosurgery. 1982;10:61-69.

14. Mackinnon SE, Doolabh VB, Novak CB, Trulock EP. Clinical outcome following nerve allograft transplantation. Plast Reconstr Surg. 2001;107:1419-1429.

15. Hudson TW, Liu SY, Schmidt CE. Engineering an improved acellular nerve graft via optimized chemical processing. Tissue Eng. 2004;10:1346-1358.

16. Gilbert TW, Sellaro TL, Badylak SF. Decellularization of tissues and organs. Biomaterials. 2006;27(19):3675-3683.

17. Gulati AK. Evaluation of acellular and cellular nerve grafts in repair of rat peripheral nerve. J Neurosurg. 1988;68:117-123.

18. Freytes DO, Badylak SF, Webster TJ, et al. Biaxial strength of multilaminated extracellular matrix scaffolds. Biomaterials 2004;25:2353-2361.

19. Lin P, Chan WC, Badylak SF, et al. Assessing porcine liverderived biomatrix for hepatic tissue engineering. Tissue Eng 2004;10:1046-1053

20. Yoo JJ, Meng J, Oberpenning F, et al. Bladder augmentation using allogenic bladder submucosa seeded with cells. Urology. 1998;51:221-225.

21. De Filippo RE, Yoo JJ, Atala A. Urethral replacement using cell seeded tubularized collagen matrices. J Urol. 2002;168:1789-1792.

22. Dahl SL, Koh J, Prabhakar V, et al. Decellularized native and engineered arterial scaffolds for transplantation. Cell Transplant. 2003;12:659-666.

23. Chen RN, Ho HO, Tsai YT, et al. Process development of an acellular dermal matrix (ADM) for biomedical applications. Biomaterials. 2004;25(13):2679-2686.

24. Woods T, Gratzer PF. Effectiveness of three extraction techniques in the development of a decellularized bone-anterior cruciate ligament-bone graft. Biomaterials. 2005;26:7339-7349.

25. Vyavahare N, Hirsch D, Lerner E, et al. Prevention of bioprosthetic heart valve calcification by ethanol preincubation. Efficacy and mechanisms. Circulation. 1997;95:479-488.

26. Goissis G, Suzigan S, Parreira DR, et al. Preparation and characterization of collagen-elastin matrices from blood vessels intended as small diameter vascular grafts. Artif Organs. 2000;24:217-223.

27. Courtman DW, Pereira CA, Kashef V, et al. Development of a pericardial acellular matrix biomaterial: biochemical and mechanical effects of cell extraction. J Biomed Mater Res. 1994;28:655-666.

28. Rieder E, Kasimir MT, Silberhumer G, et al. Decellularization protocols of porcine heart valves differ importantly in efficiency of cell removal and susceptibility of the matrix to recellularization with human vascular cells. J Thorac Cardiovasc Surg. 2004;127:399-405.

29. Gamba PG, Conconi MT, Lo Piccolo R, et al. Experimental abdominal wall defect repaired with acellular matrix. Pediatr Surg Int. 2002;18:327-331.

30. Clark JN, Ogle MF, Ashworth P, et al. Prevention of calcification of bioprosthetic heart valve cusp and aortic wall with ethanol and aluminium chloride. Ann Thorac Surg. 2005;79(3):897-904.

31. Frerichs O, Fansa H, Schicht C, Wolf G, Schneider W, Keilhoff G Reconstruction of peripheral nerves using acellular nerve grafts with implanted cultured Schwann cells. Microsurgery. 2002;22(7):311-315.

32. Krekoski CA, Neubauer D, Graham JB, et al. Metalloproteinasedependent predegeneration in vitro enhances axonal regeneration within acellular peripheral nerve grafts. $J$ Neurosci. 2002;22(23):10408-10415.

33. Kim BS, Yoo JJ, Atala A. Peripheral nerve regeneration using acellular nerve grafts. J Biomed Mater Res A. 2004;68(2):201-209.

34. Neubauer D, Graham JB, Muir D. Chondroitinase treatment increases the effective length of acellular nerve grafts. Exp Neurol. 2007;207:163-170.

35. Whitlock EL, Tuffaha SH, Luciano JP, et al. Processed allografts and type I collagen conduits for repair of peripheral nerve gaps. Muscle Nerve. 2009;39:787-799.
36. Sun F, Zhou K, Mi WJ, et al. Combined use of decellularized allogeneic artery conduits with autologous transdifferentiated adiposederived stem cells for facial nerve regeneration in rats. Biomaterials. 2011;32(32):8118-8128.

37. Zhao Z, Wnag $\mathrm{Y}$, Peng $\mathrm{J}$, et al. Improvement in nerve regeneration through a decellularized nerve graft by supplementation with bone marrow stromal cells in fibrin. Cell Transplant. 2014;23(1): 97-110.

38. Gluck T. Ueber Transplantation, Regeneration und entzündliche Neubildung. Klin Wochenschr. 1881;18:554-557.

39. Lundborg G. A 25-year perspective of peripheral nerve surgery: evolving neuroscientific concepts and clinical significance. J Hand Surg. 2000;25:391-414.

40. Verreck G, Chun I, Li Y, et al. Preparation and physico-chemical characterization of biodegradable nerve guides containing the nerve growth agent sabeluzole. Biomaterials. 2005;26:1307-1315.

41. Freed LE, Vunjak-Novakovic G, Biron RJ, et al. Biodegradable polymer scaffolds for tissue engineering. Nat Biotechnol. 1994;12: 689-693.

42. Schmidt CE, Leach JB. Neural tissue engineering: strategies for repair and regeneration. Annu Rev Biomed Eng. 2003;5:293-347.

43. Hrabak O. Industrial production of poly-3-hydroxybutyrate. FEMS Microbiol Rev. 1992;103:251-256.

44. Williams SF, Martin DP, Horowitz DM, Peoples OP. PHA applications: addressing the price performance issue: I. Tissue engineering. Int J Biol Macromol. 1999;25:111-121.

45. Hazari A, Johansson-Rudén G, Junemo-Bostrom K, et al. A new resorbable wrap-around implant as an alternative nerve repair technique. J Hand Surg Br. 1999;24:291-295.

46. Aberg M, Ljungberg C, Edin E, et al. Clinical evaluation of a resorbable wrap-around implant as an alternative to nerve repair: a prospective, assessor-blinded, randomised clinical study of sensory, motor and functional recovery after peripheral nerve repair. J Plast Reconstr Aesthet Surg. 2009;62:1503-1509.

47. Terenghi G, Mosahebi A. The interface between peripheral axons, Schwann cells and biosynthetic nerve guides. In: Aldskogius H, Fraher J, editors. Glial Interfaces in the Nervous System: Role in Repair and Plasticity. Amsterdam: IOS Press; 2002:13-20.

48. Armstrong SJ, Wiberg M, Terenghi G, et al. ECM molecules mediate both Schwann cell proliferation and activation to enhance neurite outgrowth. Tissue Eng. 2007;13(12):2863-2870.

49. Mohanna PN, Young RC, Wiberg M, et al. A composite poly-hydroxybutyrate-glial growth factor conduit for long nerve gap repairs. J Anat. 2003;203:553-565.

50. Erba P, Mantovani C, Kalbermatten DF, et al. Regeneration potential and survival of transplanted undifferentiated adipose tissuederived stem cells in peripheral nerve conduits. J Plast Reconstr Aes. 2010;63(12):e811-e817.

51. Masaeli E, Morshed M, Nasr-Esfahani MH, et al. Fabrication, characterization and cellular compatibility of poly(hydroxy alkanoate) composite nanofibrous scaffolds for nerve tissue engineering. PloS One. 2013;8(2):e57157.

52. Biazar E, Heidari KH. A nanofibrous phbv tube with Schwann cell as artificial nerve graft contributing to rat sciatic nerve regeneration across a 30-mm defect bridge. Cell Commun Adhes. 2013;20(1-2): 41-49.

53. Biazar E, Keshel SH. Chitosan-cross-linked nanofibrous PHBV nerve guide for rat sciatic nerve regeneration across a defect bridge. ASAIOJ. 2013;56(6):651-659.

54. Prabhakaran MP, Atankhan E, Ramakrishna S. Electrospun aligned $\mathrm{PHBV} /$ collagen nanofibers as substrates for nerve tissue engineering. Biotechnol Bioeng. 2013;110(10):2775-2784.

55. Kadler KE, Holmes DE, Trotter JA, et al. Collagen fibril formation. Biochem J. 1996;316:1-11.

56. Evans DG, Baser ME, McGaughran J, Sharif S, Howard E, Moran A. Malignant peripheral nerve sheath tumours in neurofibromatosis 1 . J Med Genet. 2002;39:311-314. 
57. Brown RA, Phillips JB. Cell responses to biomimetic protein scaffolds used in tissue repair and engineering. Int Rev Cytol. 2007;262:75-150.

58. Brown RA, Wiseman M, Chuo C-B, Cheema U, Nazhat SN. Ultrarapid engineering of biomimetic materials and tissues: fabrication of nano- and microstructures by plastic compression. Adv Funct Mater. 2005; 15:1762-1770.

59. Archibald S, Krarup C, Shefner J, et al. A collagen-based nerve guide conduit for peripheral nerve repair: an electrophysiological study of nerve regeneration in rodents and nonhuman primates. J Comp Neurol. 1991;306:685-696.

60. Mackinnon SE, Hudson AR, Bojanowski V, Hunter DA, Maraghi E. Peripheral-nerve injection injury with purified bovine collagen - an experimental-model in the rat. Ann Plast Surg. 1985;14:428-436.

61. Meek MF, Coert JH. US Food and Drug Administration/Conformit Europe-approved absorbable nerve conduits for clinical repair of peripheral and cranial nerves. Ann Plast Surg. 2008;60:466-472.

62. Kramer BA, Kader Ag, Klark RN. Use of the Neuro-Wrap system for severe post-electroconvulsive therapy headaches. $J E C T$. 2008;24(2):152-155.

63. Li ST, Yuen D, inventors; Collagen Matrix, Inc., assignee. Implant devices for nerve repair. United States patent US6716225 B2. April 6, 2004.

64. Li ST, Archibald SJ, Krarup C, Madison RD. Peripheral nerve repair with collagen conduits. Clin Mater. 1992;9:195-200.

65. Lohmeyer JA, Siemers F, Machens HG, et al. The clinical use of artificial nerve conduits for digital nerve repair: a prospective cohort study and literature review. J Reconstr Microsurg. 2009;25:55-61.

66. Madduri S, Feldman K, Tervoort T. Collagen nerve conduits releasing the neurotrophic factors GDNF and NGF. $J$ Controlled Release. 2010;143:168-174.

67. Yang CR, Chen JD. Preparation and biological evaluation of chitosancollagen-icariin composite scaffolds for neuronal regeneration. Neurol Sci. 2013;34:941-947.

68. Salvatore L, Madaghiele M, Parisi C, Gatti F, Sannino A. Crosslinking of micropatterned collagen based nerve guides to modulate the expected half life. J Biomed Mater Res A. Epub February 14, 2014.

69. Liu BS, Yao $\mathrm{CH}$, Hsu SH, et al. A novel use of genipin-fixed gelatin as extracellular matrix for peripheral nerve regeneration. J Biomater Appl. 2004;19:21-34.

70. Cenni E, Ciapetti G, Stea S, et al. Biocompatibility and performance in vitro of a hemostatic gelatin sponge. J Biomater Sci Polym Ed. 2000;11:685-699.

71. Gamez E, Goto Y, Nagata K, Iwaki T, Sasaki T, Matsuda. Photofabricated gelatin-based nerve conduits: nerve tissue regeneration potential. Cell Transplant. 2004;13(5):549-564.

72. Chen YS, Chang JY, Chen CY, et al. An in vivo evaluation of a biodegradable genipin-cross-linked gelatin peripheral nerve guide conduit material. Biomaterials. 2005;26:3911-3918.

73. Liu BS. Fabrication and evaluation of a biodegradable proanthocyanidin-crosslinked gelatin conduit in peripheral nerve repair. J Biomed Mater Res A. 2008;15;87(4):1092-1102.

74. Nie X, Deng M, Yang M, Liu L, Zhang Y, Wen X. Axonal regeneration and remyelination evaluation of chitosan/gelatin based nerve guide combined with transforming growth factor- $\beta 1$ and Schwann cells. Cell Biochen Biophys. 2014;68:163-172.

75. Whitworth IH, Terenghi G, Green CJ, et al. Targeted delivery of nerve growth factor via fibronectin conduits assists nerve regeneration in control and diabetic rats. Eur J Neurosci. 1995;7:2220-2225.

76. Whitworth IH, Brown RA, Dore CJ, et al. Nerve growth factor enhances nerve regeneration through fibronectin grafts. J Hand Surg. 1996;21B:514-522.

77. Ahmed Z, Brown RA. Adhesion, alignment and migration of cultured Schwann cells on ulrathin fibronectin fibres. Cell Motıl Cytoskel. 1999;42:331-343.

78. Phillips JB, Bunting SCJ, Ward Z, Hall SM, Brown RA. Fibronectin tubes as tissue engineering devices for peripheral nerve repair. Molecular, Cellular and Tissue Engineering, 2002. Proceedings of the IEEEEMBS Special Topic Conference.
79. Mosahebi A, Wiberg M, Terenghi G. Addition of fibronectin to alginate matrix improves peripheral nerve regeneration in tissue-engineered conduits. Tissue Eng. 2009;9(2):209-218.

80. Ding T, Lu WW, Zheng Y, Li Zy, Pan Hb, Luo Z. Rapid repair of rat sciatic nerve injury using a nanosilver-embedded collagen scaffold coated with laminin and fibronectin. Regen Med. 2011;6(4):437-447.

81. Kaplan DL, Mello SM, Arcidiacono S, et al. In: McGrath KKD, editor. Protein Based Materials. Boston: Birkhauser; 1998:103-131.

82. Bini E, Knight DP, Kaplan DL. Mapping domain structures in silks from insects and spiders related to protein assembly. $\mathrm{J} \mathrm{Mol} \mathrm{Biol.}$ 2004;335(1):27-40.

83. Yang Y, Chen X, Ding F, et al. Biocompatibility evaluation of silk fibroin with peripheral nerve tissues and cells in vitro. Biomaterials. 2007;28:1643-1652.

84. Huang W, Begum R, Barber T, et al. Regenerative potential of silk conduits in repair of peripheral nerve injury in adult rats. Biomaterials. 2012;33:59-71.

85. Gu Y, Zhu J, Xue C, et al. Chitosan/silk fibroin-based, Schwann cellderived extracellular matrix-modified scaffolds for bridging rat sciatic nerve gaps. Biomaterials. 2014;35(7):2253-2263.

86. Schacht K, Scheibel T. Processing of recombinant spider silk proteins into tailor-made materials for biomaterials applicayions. Curr Opin Biotech. 2014;29C:62-69.

87. Crewther WG, Fraser RDB, Lennox FG, Lindley H. The chemistry of keratins. In: Anfinsen CB Jr, Anson ML, Edsall JT, Richards FM, editors. Advances in Protein Chemistry. New York: Academic Press; 1965:191-346.

88. Lin YC, Ramadan M, Van Dyke M, et al. Keratin gel filler for peripheral nerve repair in a rodent sciatic nerve injury model. Plast Reconstr Surg. 2012;129(1):67-78.

89. Pace LA, Plate JF, Mannava S, et al. A human hair keratin hydrogel scaffold enhances median nerve regeneration in nonhuman primates: an electrophysiological and histological study. Tissue Eng Part A. 2014;20(3-4):507-517.

90. Sierpinski P, Garrett J, Ma J, et al. The use of keratin biomaterials derived from human hair for the promotion of rapid regeneration of peripheral nerves. Biomaterials. 2008;29(1):118-128.

91. Nishinari K, Takahashi R. Interaction in polysaccharide solutions and gels. Curr Opin Colloid Interface Sci. 2003;8:396-400.

92. Yu L, Dean K, Li L. Polymer blends and composites from renewable resources. Prog Polym Sci. 2006;31:576-602.

93. Eugene K, Lee YL. Implantable applications of chitin and chitosan. Biomaterials. 2003;24:2339-2349.

94. Zheng L, Cui HF. Use of chitosan conduit combined with bone marrow mesenchymal stem cells for promoting peripheral nerve regeneration. J Mater Sci Mater Med. 2010;21(5);1713-1720.

95. Haastert-Talini K, Geuna S, Dahlin LB, et al. Chitosan tubes of varying degrees of acetylation for bridging peripheral nerve defects. Biomaterials. 2013;34(38):9886-9904.

96. Carvalho CR, Correia MA, Oliveire JM, Reis RL. Chitosan nanofibers as scaffolds for peripheral nerve regeneration. J Tissue Eng Reg Med. 2013;7(Supp 1):6-52.

97. Hsu SH, Kuo WC, Chen YT, et al. New nerve regeneration strategy combining laminin-coated chitosan conduits and stem cell therapy. Acta Biomater. 2013;9(5):6606-6615.

98. Burdick AJ, Prestwich GD. Hyaluronic acid hydrogels for biomedical applications. Adv Mater. 2011;23(12):H41-H56.

99. Suri S, Schmidt CR. Cell-laden hydrogel constructs of hyaluronic acid, collagen, and laminin for neural tissue engineering. Tissue Eng Part A. 2010;16(5):1707-1713.

100. Guan S, Zhang XL, Lin XM, Liu TQ, Ma XH, Cui ZF. Chitosan/ gelatin porous scaffolds containing hyaluronic acid and heparan sulfate for neural tissue engineering. J Biomater Sci Polym Ed. 2013;24(8):999-1014.

101. Tian B, Liu J, Dvir T, et al. Macroporous nanowire nanoelectronic scaffolds for synthetic tissues. Nat Mater. 2012;11:986-994. 
102. Lu MC, Huang YT, Lin JH, et al. Evaluation of a multi-layer microbraided polylactic acid fiber-reinforced conduit for peripheral nerve regeneration. J Mater Sci Mater Med. 2009;20:1175-1180.

103. Hsu SH, Chan SH, Chiang CM, et al. Peripheral nerve regeneration using a microporous polylactic acid asymmetric conduit in a rabbit long-gap sciatic nerve transection model. Biomaterials. 2011:32:3764-3775.

104. Matsumine H, Sasaki R, Yamato M, Okano T, Sakurai H. A polylactic acid non-woven nerve conduit for facial nerve regeneration in rats. J Tissue Eng Regen Med. 2014;8(6):454-462.

105. Ni HC, Tseng TC, Chen JR, Hsu SH, Chiu IM. Fabrication of bioactive conduits containing the fibroblast growth factor 1 and neural stem cells for peripheral nerve regeneration across a $15 \mathrm{~mm}$ critical gap. Biofabrication. 2013;5:035010.

106. Evans GRD, Brandt K, Widmer MS, et al. In vivo evaluation of poly(L-lactic acid) porous conduits for peripheral nerve regeneration. Biomaterials. 1999;20:1109-1115.

107. Rutkowski GE, Miller CA, Jeftinija S, Mallapragada SK. Synergistic effects of micropatterned biodegradable conduits and Schwann cells on sciatic nerve regeneration. J Neural Eng. 2004;1:151-157.

108. Li J, McNally H, Shi R. Enhanced neurite alignment on micropatterned poly-L-lactic acid films. J Biomed Mater Res Part A. 2008; 87:392-404.

109. Liu JJ, Wang CY, Wang JG, et al. Peripheral nerve regeneration using composite poly(lactic acid-caprolactone)/nerve growth factor conduits prepared by coaxial electrospinning. J Biomed Mater Res Part A. 2011;96:1-20.

110. Xu H, Holzwarth JM, Yan Y, et al. Conductive PPY/PDLLA conduit for peripheral nerve regeneration. Biomaterials. 2014;35:225-235.

111. Tabesh H, Amoabediny G, Nik NS, et al. The role of biodegradable engineered scaffolds seeded with Schwann cells for spinal cord regeneration. Neurochem Int. 2009;54:73-83.

112. Dellon AL, Chang BW. An alternative incision for approaching recurrent median nerve compression at the wrist. Plast Reconstr Surg. 1992;89:576-578.

113. Costa HJZR, Bento RF, Salomone R, et al. Mesenchymal bone marrow stem cells within polyglycolic acid tube observed in vivo after six weeks enhance facial nerve regeneration. Brain Res. 2013;1510:10-21.

114. Sundback C, Hadlock T, Cheney M, et al. Manufacture of porous polymer nerve conduits by a novel low-pressure injection molding process. Biomaterials. 2003;24:819-830.

115. Yang Y, De Laporte L, Rives CB, et al. Neurotrophin releasing single and multiple lumen nerve conduits. J Control Release. 2005; 104:433-446.

116. Wen X, Tresco PA. Fabrication and characterization of permeable degradable poly(DL-lactide-co-glycolide) (PLGA) hollow fiber phase inversion membranes for use as nerve tract guidance channels. Biomaterials. 2006;27:3800-3809.

117. Oh SH, Kim JH, Song KS, et al. Peripheral nerve regeneration within an asymmetrically porous PLGA/Pluronic F127 nerve guide conduit. Biomaterials. 2008;29:1601-1609.

118. Lee JY, Bashur CA, Goldstein AS, et al. Polypyrrole-coated electrospun PLGA nanofibers for neural tissue applications. Biomaterials. 2009;30:4325-4335.

119. Shen H, Shen ZL, Zhang PH, et al. Ciliary neurotrophic factor-coated polylactic-polyglycolic acid chitosan nerve conduit promotes peripheral nerve regeneration in canine tibial nerve defect repair. $J$ Biomed Mater Res B Appl Biomater. 2010;95:161-170.

120. Daly WT, Knight AM, Wang H, et al. Comparison and characterization of multiple biomaterial conduits for peripheral nerve repair. Biomaterials. 2013;34:8630-8639.

121. Sun M, Kingham PJ, Reid AJ, et al. In vitro and in vivo testing of novel ultra thin PCL and PCL/PLA blend films as peripheral nerve conduit. J Biomed Mater Res Part A. 2010;93:1470-1481.

122. Oliveira JT, Almeida FM, Biancalana A, et al. Mesenchymal stem cells in a polycaprolactone conduit enhance median-nerve regeneration, prevent decrease of creatine phosphokinase levels in muscle, and improve functional recovery in mice. Neuroscience. 2010;170:1295-1303.
123. Moroder P, Runge MB, Wang H, et al. Material properties and electrical stimulation regimens of polycaprolactone fumarate-polypyrrole scaffolds as potential conductive nerve conduits. Acta Biomater. 2011;7:944-953.

124. Rui J, Dadsetan M, Runge MB, et al. Controlled release of vascular endothelial growth factor using poly-lactic-co-glycolic acid microspheres: in vitro characterization and application in polycaprolactone fumarate nerve conduits. Acta Biomater. 2012;8:511-518.

125. Frattini F, Lopes FRP, Almeida FM, et al. Mesenchymal stem cells in a polycaprolactone conduit promote sciatic nerve regeneration and sensory neuron survival after nerve injury. Tissue Eng Part A. 2012;18:2030-2039.

126. Mobasseri SA, Terenghi G, Downes S. Micro-structural geometry of thin films intended for the inner lumen of nerve conduits affects nerve repair. J Mater Sci Mater Med. 2013;24(7):1639-1647.

127. Kim JR, Oh SH, Kwon GB, et al. Acceleration of peripheral nerve regeneration through asymmetrically porous nerve guide conduit applied with biological/physical stimulation. Tissue Eng Part A. 2013;19:2674-2685.

128. Radulescu D, Dhar S, Young CM, et al. Tissue engineering scaffolds for nerve regeneration manufactured by ink-jet technology. Mater $\mathrm{Scl}$ Eng C. 2007;27:534-539.

129. McConnell MP, Dhar S, Nguyen T, et al. Nerve growth factor expression response to induction agent booster dosing in transfected human embryonic kidney cells. Plast Reconstr Surg. 2005;115(2):506-514.

130. Chiriac S, Facca S, Diaconu M, et al. Experience of using the bioresorbable copolyester poly(DL-lactide- $\varepsilon$-caprolactone) nerve conduit guide Neurolac ${ }^{\mathrm{TM}}$ for nerve repair in peripheral nerve defects: report on a series of 28 lesions. J Hand Surg Eur. 2011;37:342-349.

131. Yin D, Wang X, Yan Y, Zhang R. Preliminary studies on peripheral nerve regeneration using a new polyurethane conduit. J Bioact Compat Polym. 2007;22:143-159.

132. Niu Y, Chen KC, He T, et al. Scaffolds from block polyurethanes based on poly(3-caprolactone) (PCL) and poly(ethylene glycol) (PEG) for peripheral nerve regeneration. Biomaterials. 2014;35: 4266-4277.

133. Rutkowski GE, Heath CA. Development of a bioartificial nerve graft. II. Nerve regeneration in vitro. Biotechnol Prog. 2002;18:373-379.

134. Shokrgozar MA, Mottaghitalab F, Mottaghitalab V, et al. Fabrication of porous chitosan/poly(vinyl alcohol) reinforced single-walled carbon nanotube nanocomposites for neural tissue engineering. J Blomed Nanotechnol. 2011;7:1-9.

135. Alhosseini SN, Moztarzadeh F, Mozafari M, et al. Synthesis and characterization of electrospun polyvinyl alcohol nanofibrous scaffolds modified by blending with chitosan for neural tissue engineering. Int J Nanomed. 2012;7:25-34.

136. Bergethon PR, Trinkaus-Randall V, Franzblau C. Modified hydroxyethylmethacrylate hydrogels as a modelling tool for the study of cellsubstratum interactions. J Cell Sci. 1989;92:111-121.

137. Lee J, Cuddihy MJ, Kotov NA. Three-dimensional cell culture matrices: state of the art. Tissue Eng Part B. 2008;14:61-86.

138. Dhoot NO, Tobias CA, Fischer I, et al. Peptide-modified alginate surfaces as a growth permissive substrate for neur-ite outgrowth J Biomed Mater Res. 2004;71A:191-200.

139. Yu TT, Shoichet MS. Guided cell adhesion and outgrowth in peptidemodified channels for neural tissue engineering. Biomaterials. 2005;26:1507-1514.

140. Gupta D, Tator CH, Shoichet MS. Fast-gelling injectable blend of hyaluronan and methylcellulosefor intrathecal, localized delivery to the injured spinal cord. Biomaterials. 2006:27:2370-2379.

141. Wang X, Cui T, Yan Y, Zhang R. Peroneal nerve regeneration using a unique bilayer polyurethane-collagen guide conduit. J Bioact Compat Polym. 2009;24(2):109-127.

142. Xu H, Yan Y, Li S. PDLLA/chondroitin sulfate/chitosan/NGF conduits for peripheral nerve regeneration. Biomaterials. 2011;32: 4506-4515. 
143. Lee BK, Ju YM, Cho JG, et al. End-to-side neurorrhaphy using an electrospun PCL/collagen nerve conduit for complex peripheral motor nerve regeneration. Biomaterials. 2012;33:9027-9036.

144. Yucel D, Torun Kose G, Hasirc1 V. Polyester based nerve guidance conduit design. Biomaterials. 2010;31(7):1596-1603.

145. Yucel D, Torun Kose G, Hasirc1 V. Tissue engineered, guided nerve tube consisting of aligned neural stem cells and astrocytes. Biomacromolecules. 2010;11:3584-3591.

146. Cooper A, Bhattarai N, Zhang M. Fabrication and cellular compatibility of aligned chitosan-PCL fibers for nerve tissue regeneration. Carbohydr Polym. 2011;85(1):149-156.

147. Kiyotani T, Teramachi M, Takimoto Y, et al. Nerve regeneration across a $25-\mathrm{mm}$ gap bridged by a polyglycolic acid-collagen tube: a histological and electrophysiological evaluation of regenerated nerves. Brain Res. 1996;740:66-74.
148. Matsumato K, Ohnishi K, Kiyotani T, et al. Peripheral nerve regeneration across an 80-mm gap bridged by a polyglycolic acid (PGA)collagen tube filled with laminin-coated collagen fibers: a histological and electrophysiological evaluation of regenerated nerves. Brain Res. 2000;868:315-328.

149. Toba T, Nakamura T, Shimizu Y, et al. Regeneration of canine peroneal nerve with the use of a polyglycolic acid-collagen tube filled with laminin-soaked collagen sponge: a comparative study of collagen sponge and collagen fibers as filling materials for nerve conduits. J Biomed Mater Res. 2001;58:622-630.

150. Nakamura T, Inada Y, Fukuda S, et al. Experimental study on the regeneration of peripheral nerve gaps through a polyglycolic acid-collagen (PGA-collagen) tube. Brain Res. 2004;1027: $18-29$.

\section{Publish your work in this journal}

Medical Devices: Evidence and Research is an international, peerreviewed, open access journal that focuses on the evidence, technology, research, and expert opinion supporting the use and application of medical devices in the diagnosis, treatment and management of clinical conditions and physiological processes. The identification of novel devices and optimal use of existing devices which will lead to improved clinical outcomes and more effective patient management and safety is a key feature. The manuscript management system is completely online and includes a quick and fair peer-review system. Visit http://www. dovepress.com/testimonials.php to read real quotes from authors.

Submit your manuscript here: http://www.dovepress.com/medical-devices-evidence-and-research-journal 